\title{
Characteristics of Synoptic Conditions for Heavy Snowfall in Western to Northeastern Japan Analyzed by the 5-km Regional Climate Ensemble Experiments
}

\author{
Hiroaki KAWASE \\ Meteorological Research Institute, Japan Meteorological Agency, Tsukuba, Japan \\ Takahiro SASAI, Takeshi YAMAZAKI \\ Tohoku University, Sendai, Japan \\ Rui ITO \\ Japan Meteorological Business Support Center, Tsukuba, Japan \\ Koji DAIRAKU \\ Integrated Research on Disaster Risk Reduction Division, \\ National Research Institute for Earth Science and Disaster Prevention, Tsukuba, Japan \\ Shiori SUGIMOTO \\ Japan Agency for Marine-Earth Science and Technology, Yokohama, Japan \\ Hidetaka SASAKI, Akihiko MURATA, and Masaya NOSAKA \\ Meteorological Research Institute, Japan Meteorological Agency, Tsukuba, Japan \\ (Manuscript received 12 August 2017, in final form 12 January 2018)
}

\begin{abstract}
Geographical distributions of heavy snowfall, especially in the Pacific Ocean side of Japan, have not been previously elucidated due to low occurrence frequency of heavy snowfall and limited number of snow observation points. This study investigates the characteristics of synoptic conditions for heavy daily snowfall from western to northeastern Japan in the present climate, analyzing high-resolution regional climate ensemble experiments with 5-km grid spacing. The Japanese 55-year Reanalysis (JRA-55) and the 10-ensemble members of the database for Policy Decision making for Future climate change (d4PDF) historical experiments are applied to the lateral boundary conditions of the regional climate model. Dynamical downscaling using d4PDF (d4PDF-DS) enabled us to evaluate much heavier snowfall events than those simulated by dynamical downscaling using JRA-55 (JRA55-DS).

Over the Sea of Japan side, heavy snowfall occurs due to cold air outbreaks, while over the Pacific Ocean side, heavy snowfall is brought about by extratropical cyclones passing along the Pacific Ocean coast. A comparison
\end{abstract}

Corresponding author: Hiroaki Kawase, Meteorological

Research Institute, Japan Meteorological Agency, 1-1,

Nagamine, Tsukuba, Ibaraki 305-0052, Japan

E-mail: hkawase@mri-jma.go.jp

J-stage Advance Published Date: 30 January 2018

CThe Author(s) 2018. This is an open access article published by the Meteorological Society of Japan under a Creative Commons Attribution 4.0 International (CC BY 4.0) license (http://creativecommons.org/license/by/4.0). 
between JRA55-DS and d4PDF-DS indicated that heavier snowfall can occur due to more developed extratropical cyclones and enhanced cold air damming in the Tokyo metropolitan area. The geographical distributions of extremely heavy snowfall are different between two typical synoptic conditions, i.e., cold air outbreaks and extratropical cyclones. The difference is much clearer in the extremely heavy snowfall events than in all snowfall events. Heavy daily snowfall occurs in January and February on the Pacific Ocean side, in December and January on the Sea of Japan side, and in November and March in high mountainous areas. Saturated water vapor pressure is largest around $0^{\circ} \mathrm{C}$ under the snowing conditions. Synoptic conditions from late fall to winter are closely related to preferable conditions for heavy snowfall over the mountainous areas where the surface air temperature is much less than $0^{\circ} \mathrm{C}$ in the heavy snowfall events.

Keywords heavy daily snowfall; winter monsoon; extratropical cyclone; regional climate ensemble experiments

\section{Introduction}

Mountainous areas along the Sea of Japan side receive a lot of snowfall in winter. The northwesterly wind, known as the East Asian winter monsoon, is triggered by the thermal contrast between land and ocean and prevails over the Japanese archipelago in winter. The dry and cold northwesterly from the continent obtains a large amount of water vapor from the warm Sea of Japan, leading to enormous snowfall along the Sea of Japan, especially in mountainous areas. On the other hand, the Pacific Ocean side of Japan is on the leeward side of the northwesterly, leading to dry and fine weather during most of the winter. However, Japan sometimes has snowfall on the Pacific Ocean side when an extratropical cyclone, called a "southern coastal extratropical cyclone," passes near its southern coast (Yamamoto 1984; Takano 2002).

Heavy snowfall isolates towns and causes serious traffic congestion, traffic accidents, and surface avalanches in mountainous areas. Strong cold air outbreaks can bring about heavy snowfall in the mountainous areas along the Sea of Japan (Iwamoto et al. 2008). Warmer sea surface temperatures (SSTs) can also induce heavier snowfall along the Sea of Japan (Hirose and Fukudome 2006; Takahashi et al. 2013; Fujita et al. 2014). In contrast, over the coastal areas along the Sea of Japan, meso- $\beta$ and meso- $\gamma$ scale phenomena such as local-scale depressions, local convergences induced by land breezes, cause heavy snowfall (e.g., Eito et al. 2005; Iwamoto et al. 2008). The convergence zone appearing on the leeward side of the Korean Peninsula, called the Japan sea polar air mass convergence zone (hereafter, JPCZ), causes heavy snowfall in the coastal areas in western and central Japan (Nagata et al. 1986; Ohigashi and Tsuboki 2007).
Southern coastal extratropical cyclones occasionally cause heavy snowfall along the Pacific Ocean, where three of the largest Japanese urban areas are located, i.e., the Tokyo, Nagoya, and Osaka urban areas. In these areas, the societal preparation for heavy snowfall is insufficient because of few heavy snowfall events. In February 2014, extremely heavy snowfall due to the developed southern coastal extratropical cyclone hit the Kanto region (Honda et al. 2016; Yamazaki et al. 2015; Araki 2016; Ando and Ueno 2015; Iyobe et al. 2015; Kawashima et al. 2015), causing damages to urban and suburban functions. Yamazaki et al. (2015) and Honda et al. (2016) analyzed the atmospheric conditions of the heavy snowfall on February 14, 2014. They compared this event with fourteen and four past heavy snowfall events. Generally snowfall occurs at around $0^{\circ} \mathrm{C}$ in Tokyo, meaning that snowfall is quite sensitive to lower atmospheric temperatures (Fujibe 2001). When a southern coastal extratropical cyclone passes, snowfall is influenced by multiple factors, including the strength of the extratropical cyclone, cold air damming (Bailey et al. 2003) due to northern high pressure, adiabatic cooling due to melting and evaporating precipitation, the local coastal front, and ice nuclei in cloud formation (e.g., Fujibe 2001; Araki and Murakami 2015).

Synoptic conditions bringing heavy snowfall in the inland area in central Japan differ from those along the Sea of Japan or the Pacific Ocean. A study by Ando and Ueno (2015) focused on past heavy snowfall and rainfall events in the inland areas of central Japan. They stated that heavy snowfall and rainfall occurred around the northern part of inland mountains under typical winter monsoon pressure patterns. In other inland areas of central Japan, heavy snowfall and rainfall occur when southern coastal extratropical cyclones are passing. 
Previous studies have focused on the mechanism of heavy snowfall during specific events in Japan, such as winter monsoons, local circulations, and southern coastal extratropical cyclones. Using the observational snowfall data, some studies have shown the horizontal pattern of snowfall and rainfall in Japan (e.g., Wakisaka 1986; Ando and Ueno 2015). Suda and Ueno (2014) defined a border of weather in inland areas based on observations. It is, however, difficult to evaluate the possibility of extremely heavy snowfall events and understand the detailed geographical distribution of heavy snowfall, especially on the Pacific Ocean side of Japan, due to the lack of past heavy snowfall events. Japan has a lot of complex mountains and large mountain ranges from the northeast to the west of the main island. The horizontal distribution of snowfall is strongly influenced by these large mountain ranges.

Recently, state-of-art regional weather and climate models have simulated the heavy snowfall induced by local convergence zones, extratropical cyclones, and meso- $\beta$ vorticities (Saito et al. 1996; Eito et al. 2005). Cloud-resolving models enable us to understand in detail the mechanisms of heavy snowfall. However, the number of experiments have been limited because of limited computational resources. Therefore, there are few studies in Japan that have used large numbers of ensemble experiments to analyze extremely heavy snowfall statistically and horizontally.

On the other hand, to evaluate the impact of global warming on global and local climate extremes, large ensemble global and regional climate experiments have been conducted and released as a database for Policy Decision making for Future climate change (hereafter, d4PDF) (Kawase et al. 2016; Mizuta et al. 2017; Endo et al. 2017). This database has approximately 3,000 years of regional climate experiments around Japan in the present climate, which enabled us to evaluate phenomena such as extremely heavy precipitation, strong tropical cyclones, and extremely high temperatures. Analyzing the regional climate experiments of d4PDF, Kawase et al. (2016) showed that, under the Representative Concentration Pathway (RCP) 8.5 scenario, the frequency of heavy daily snowfall could increase over mountainous areas in the middle of Japan by the end of the $21^{\mathrm{ST}}$ century.

However, the horizontal grid spacing in the regional climate experiment was $20 \mathrm{~km}$, which was too coarse to resolve the complicated topography in Japan (See Fig. 1 in Kawase et al. 2016), resulting in less vertical motion and less orographic enhancement of precipitation. The $20-\mathrm{km}$ regional climate model overestimated and underestimated winter precipitation on the Pacific Ocean side and the Sea of Japan side, respectively (Ishizaki et al. 2012; Kawase et al. 2015, 2016). As stated above, the snowfall in Japan is strongly influenced by complicated topography (Akiyama 1981; Iwamoto et al. 2008; Suda and Ueno 2014). It is difficult to discuss in detail the horizontal distribution of heavy snowfall. Higher-resolution ensemble regional climate experiments are required to statistically and horizontally understand the distribution of heavy snowfall.

In this study, we conducted a dynamical downscaling with $5-\mathrm{km}$ grid spacing from 10 -ensemble members of d4PDF historical regional climate experiments. The purpose of this study is to clarify the characteristics of synoptic conditions that cause extremely heavy daily snowfall based on the $5-\mathrm{km}$ regional climate ensemble experiments. In Section 2, the specifications of regional climate experiments and experimental designs are presented. The methodology of classifying sea level pressure (SLP) patterns is also explained. In Section 3, we show the results of the cumulative frequency distribution of daily snowfall, the horizontal distribution of heavy daily snowfall, and composite analyses of heavy daily snowfall events. In Section 4, we discuss the SLP patterns causing heavy daily snowfall in each area. Our results are summarized in Section 5.

\section{Methods}

\subsection{Specifications of regional climate model and simulation designs}

We used a nonhydrostatic regional climate model (NHRCM) developed by the Meteorological Research Institute, Japan Meteorological Agency (Sasaki et al. 2008). The specifications of the NRHCM are summarized in Table 1. The bulk-type cloud microphysics (Ikawa et al. 1991) and the Kain-Fritsch convective parameterization scheme (Kain and Fritsch 1993) were used to calculate the precipitation process. The physical processes of the atmospheric boundary layer and of the land surface were calculated using the Mellor-Yamada-Nakanishi-Niino (MYNN) Level 3 model (Nakanishi and Niino 2004) and the improved MRI/JMA Simple Biosphere (iSiB) model (Hirai and Oh'izumi 2004), respectively. A clear-sky radiation scheme (Yabu et al. 2005) and a cloud radiation scheme (Kitagawa 2000) were used for the radiation processes. The NHRCM uses the Square Prism Urban Canopy Scheme (SPUC) (Aoyagi and Seino 2011) to assess the impact of the urban areas on climate. The specifications of the NRHCM are almost the 
Table 1. Specification of the regional climate model

\begin{tabular}{ll}
\hline Numerical model & Nonhydrostatic Regional Climate Model (Sasaki et al. 2008) \\
Horizontal resolution & $5 \mathrm{~km}$ \\
Grid number & $321 \times 301 \times 50$ \\
Microphysics & Bulk-type cloud microphysics (Ikawa et al.1991) \\
Convective precipitation & Kain-Fritsch convective parameterization scheme (Kain and Fritsch 1993) \\
Radiation process & Clear-sky radiation scheme (Yabu et al. 2005) \\
& Cloud radiation scheme (Kitagawa 2000) \\
Boundary-layer process & Mellor-Yamada-Nakanishi-Niino (MYNN) Level 3 (Nakanishi and Niino 2004) \\
Land surface process & Improved MRI/JMA Simple Biosphere (iSiB) (Hirai and Oh'izumi 2004) \\
Urban model & Square Prism Urban Canopy Scheme (SPUC) (Aoyagi and Seino 2011) \\
\hline
\end{tabular}

(a) Model domains and topography

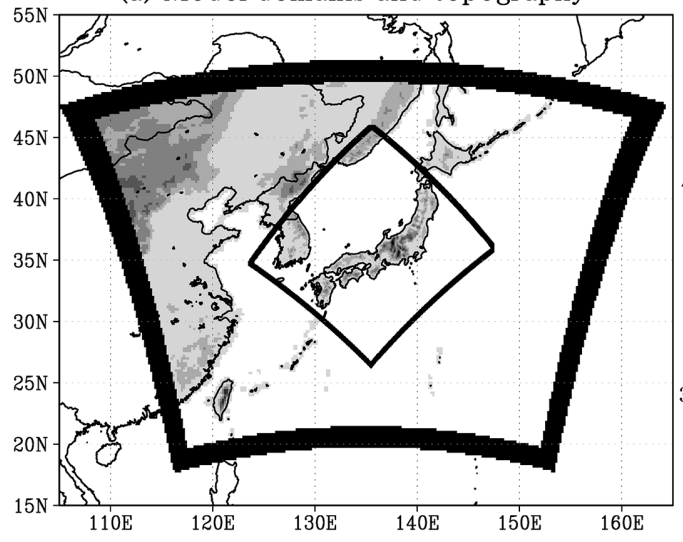

(b) Geographical locations

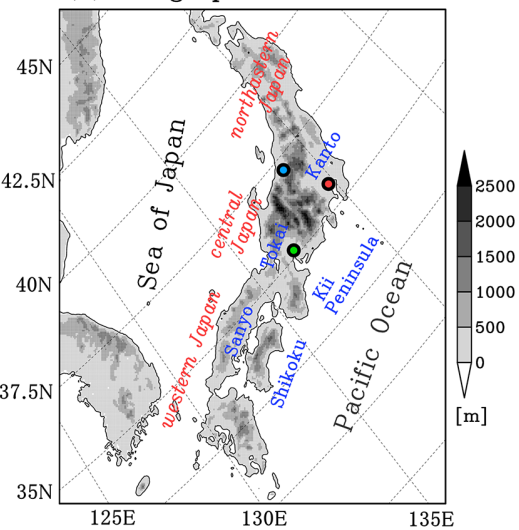

Fig. 1. Model domain and geographical map of the analysis area. (a) Outer and inner model domains and orography. Black areas are model boundaries of $20-\mathrm{km}$ and $5-\mathrm{km}$ simulations. Gray shadings represent orography. (b) Locations of AMeDAS stations used in Figs. 6-9 (colored circles) and names of regions. Red, blue, and green circles with thick black lines represent Tokyo, Tokamachi, and Nagoya, respectively.

same as those used in Murata et al. (2015), except for the SPUC. The horizontal grid interval was $5 \mathrm{~km}$. The calculation domains are shown in Fig. 1. In this study, envelope-type mountains were used in the $5-\mathrm{km}$ NHRCM because the averaged altitude of mountains in the 5-km NHRCM was much lower than the actual altitudes of mountains in Japan. It has been pointed out that, in regional climate models, lower mountains result in the underestimation and overestimation of winter precipitation on the Sea of Japan side and the Pacific Ocean side, respectively (Ishizaki et al. 2012; Kawase et al. 2015).

Lateral boundary conditions of the $5-\mathrm{km}$ NHRCM were the d4PDF regional climate experiments with 20-km grid spacing (Mizuta et al. 2017). We used first 10 -ensemble members in the historical climate simulation and the 31 years from 1980 to 2010 for each member (Table 2). Experiments are called d4PDFDS01 to d4PDF-DS10. The 10-ensemble members are called d4PDF-DSall. According to the methodology in Mizuta et al. (2017), the atmospheric boundary conditions of each ensemble member were assumed to be independent in d4PDF regional climate experiments. Timings of daily heavy snowfall events were different among 10 d4PDF-DS experiments. The total number of years in d4PDF-DSall was 310, and the experiments ran from July 24 of each year to August of the following year. Calculation results from October were used in this study.

As compared with d4PDF-DS, other dynamical downscalings were performed using the Japanese 55-year Reanalysis (Kobayashi et al. 2015) for the initial and lateral boundary conditions (hereafter, JRA55-DS). Since the horizontal grid interval of the 
Table 2. Experimental design

\begin{tabular}{lclrc}
\hline Experiment name & $\begin{array}{c}\text { Ensemble } \\
\text { member }\end{array}$ & Initial and lateral boundary conditions & Grid spacing & Integration term \\
\hline JRA55-DS & - & JRA55 (Kobayashi et al. 2015) & $\begin{array}{r}20 \mathrm{~km} \\
5 \mathrm{~km}\end{array}$ & $\begin{array}{c}1980 / 81-2010 / 11 \\
31 \text { years }\end{array}$ \\
d4PDF-DSxx & 10 & d4PDF 20kmNHRCM (Mizuta et al. 2017) & $5 \mathrm{~km}$ & $\begin{array}{c}1980 / 81-2010 / 11 \\
31 \text { years }\end{array}$ \\
\hline
\end{tabular}

JRA-55 is 1.25 degrees, dynamical downscaling was conducted by the NHRCM with $20-\mathrm{km}$ grid spacing. The model domain, physical schemes, and parameters were the same as those in d4PDF 20-km regional climate experiments. Then, dynamical downscalings were conducted using the NHRCM with $5-\mathrm{km}$ grid spacing, and the experimental design was similar to that of the d4PDF-DS.

The simulations were compared with the Automated Meteorological Data Acquisition System (AMeDAS), which is a dense observation network maintained by the JMA. We picked up the nearest model grids of AMeDAS, where the altitude difference is less than $150 \mathrm{~m}$. The basic elements of AMeDAS are precipitation, temperature, wind, and isolation. Some AMeDAS stations observe snow depth. The JMA defines hourly snowfall as an hourly increment of snow depth. Daily snowfall is a sum of the hourly snowfall. We used the same definitions in our experiments to calculate the daily snowfall. In Section 4, we also used the snowfall calculated by microphysics and cumulus convection schemes in the NHRCM to discuss the horizontal distribution of snowfall and rainfall over land and ocean.

\subsection{Classification of pressure patterns}

We classified the sea level pressure (SLP) patterns using zonal and meridional gradients of daily SLP. In Japan, two typical SLP patterns cause heavy daily snowfall. One is a cold air outbreak pattern, i.e., the winter monsoon pattern, and the other is the extratropical cyclone pattern. When the winter monsoon prevails over Japan, anticyclones prevail over the Eurasian continent (west of Japan), and extratropical cyclones develop east of Japan. Therefore, the SLP is higher west of Japan and lower east of Japan; this is called a west-high east-low (hereafter WhEl) pattern. When the extratropical cyclone passes south of Japan, the SLP is lower in Japan's south and higher in the north; this is called a north-high south-low ( $\mathrm{NhSl}$ ) pattern. Therefore, we have defined the two basic patterns using daily mean SLP. The meridional SLP gradient $\left(d P_{n s}\right)$ between $3^{\circ}$ north $\left(P_{n}\right)$ and $3^{\circ}$ south $\left(P_{s}\right)$, and the zonal SLP gradient $\left(d P_{w e}\right)$ between $3^{\circ}$ west $\left(P_{w}\right)$ and $3^{\circ}$ east $\left(P_{e}\right)$ from each model grid, were calculated as follows:

$$
\begin{aligned}
& d P_{n s}=P_{n}-P_{s}, \\
& d P_{w e}=P_{w}-P_{e} .
\end{aligned}
$$

Then, we defined the following patterns:

$$
\begin{aligned}
& d P_{n s}>5 \mathrm{hPa}: \mathrm{NhSl} \text { pattern } \\
& 5 \mathrm{hPa} \geq d P_{n s}>0 \mathrm{hPa} \text { and } d P_{n s} \geq d P_{w e}: \\
& \quad \text { NhSl pattern } \\
& 5 \mathrm{hPa} \geq d P_{n s}>0 \mathrm{hPa} \text { and } d P_{n s}<d P_{w e}: \\
& \quad \text { WhEl pattern } \\
& d P_{n s} \leq 0 \mathrm{hPa} \text { and } d P_{w e}>0 \mathrm{hPa}: \text { WhEl pattern } \\
& d P_{n s} \leq 0 \mathrm{hPa} \text { and } d P_{w e} \leq 0 \mathrm{hPa}: \text { Other pattern }
\end{aligned}
$$

Figure 2 shows typical days of WhEl and NhSl patterns in JRA55-DS.

\section{Results and discussion}

\subsection{Simulation skills}

Figure 3 shows scatter diagrams of the climatological surface air temperature at $1.5 \mathrm{~m}$ (TAS) and precipitation in winter (from December to February: DJF) between AMeDAS and NHRCM with 5-km grid spacing. Climatology of winter TAS and precipitation is calculated using 25 years from 1985/86 to 2009/10. Both JRA55-DS and d4PDF-DS01 well simulate the observed winter TAS, while both experiments have cold biases at around $0^{\circ} \mathrm{C}$. Since both experiments show similar biases, this bias was not caused by atmospheric boundary conditions between JRA-55 and d4PDF. Table 3 summarizes the biases, root mean square errors (RMSEs), correlation coefficients, and regressions in JRA55-DS and 10 d4PDF-DSs.

The winter precipitation total is also well simulated by JRA55-DS and d4PDF-DS. The correlation is, however, lower over $400 \mathrm{~mm}$. Precipitation is slightly overestimated in d4PDF-DS01. Most d4PDF-DSs also show a similar overestimation of winter precipitation (Fig. 3d, Table 3). The RMSEs in d4PDF-DSs are similar to those in JRA55-DS. The positive biases of precipitation are derived from the atmospheric bound- 
(a) WhEl pattern at Tokamachi [Dec. 18, 2009]

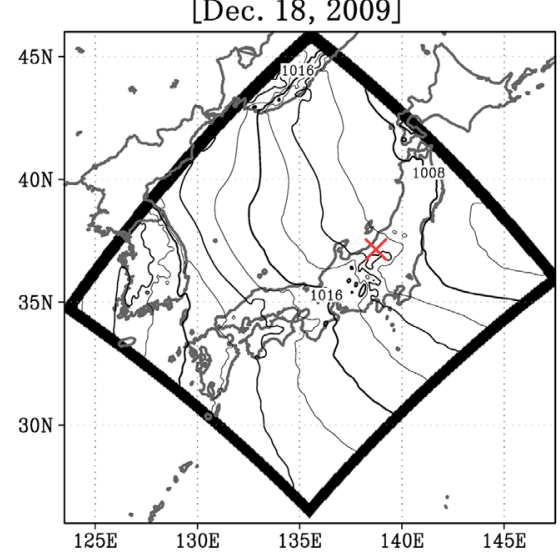

(b) Typical NhSl pattern at Tokyo

[Feb. 12, 1994]

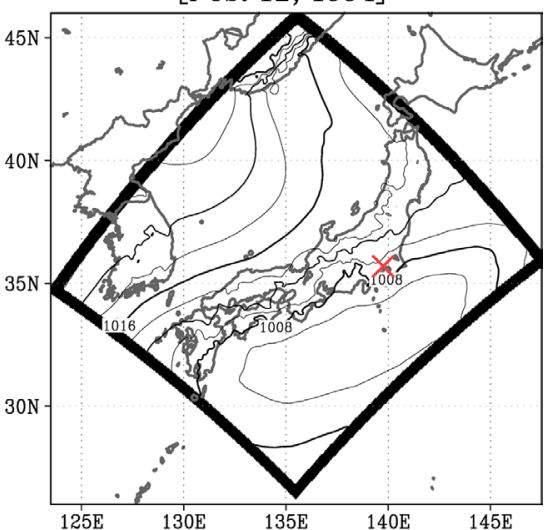

Fig. 2. Typical days of WhEl and NhSl patterns in JRA55-DS. (a) WhEl pattern at Tokamachi on December 18, 2009, and (b) NhS1 pattern at Tokyo on February 12, 1994. Red cross marks represent the locations of (a) Tokamachi and (b) Tokyo.

JRA55-DS

(a) DJF temperature $\left[{ }^{\circ} \mathrm{C}\right]$

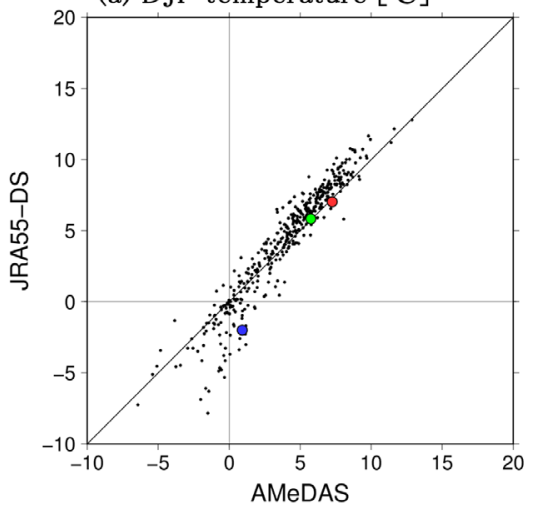

(b) DJF precipitation $[\mathrm{mm}]$

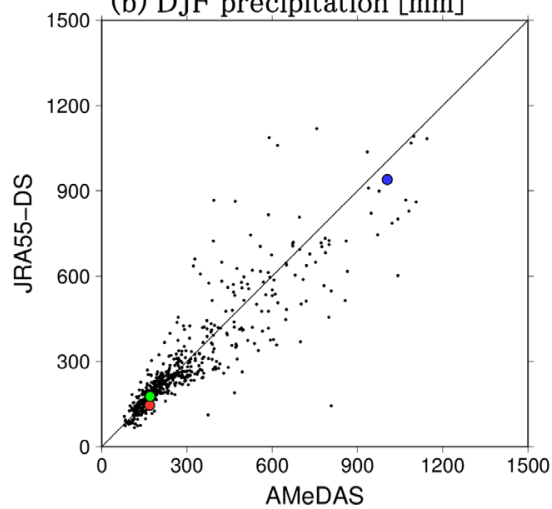

d4PDF-DS

(c) DJF temperature $\left[{ }^{\circ} \mathrm{C}\right]$

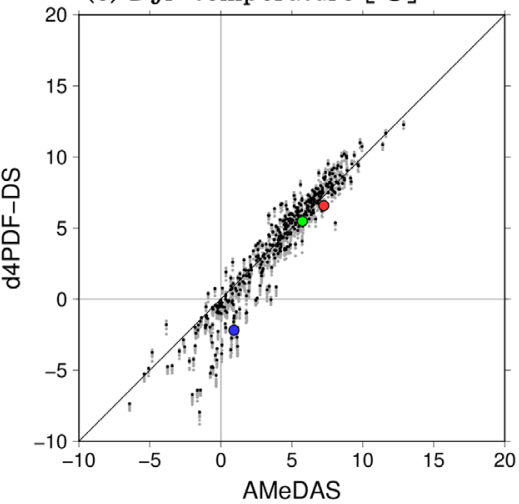

(d) DJF precipitation $[\mathrm{mm}]$

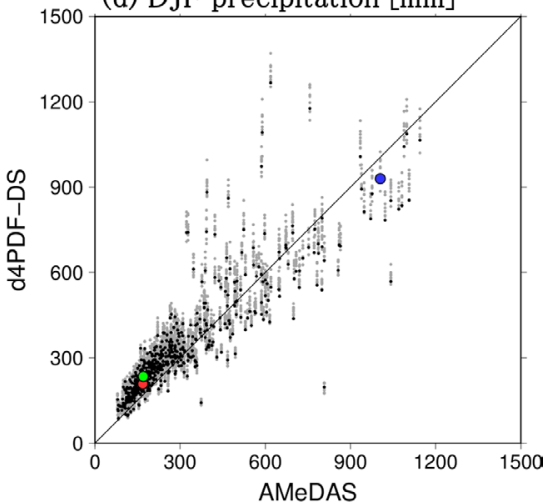

Fig. 3. Scatter diagram of climatological $(a, c)$ winter mean surface air temperature and (b, d) winter precipitation total between $(a, b)$ JRA55-DS and AMeDAS and (c, d) d4PDF-DS01 and AMeDAS. Red, blue, and green circles represent Tokyo, Tokamachi, and Nagoya, respectively, in d4PDF-DS01. In Figs. 3c and 3d, black circles represent d4PDF-DS01, and gray circles represent the other members (d4PDF-DS02 to d4PDF-DS10). 
Table 3. Simulation skills of (a) the winter mean surface air temperature and (b) the winter precipitation total.

The skills are evaluated by a bias, root mean square error (RMSE), correlation, and regression.

(a) Winter mean surface air temperature $\left[{ }^{\circ} \mathrm{C}\right]$

\begin{tabular}{lcccc}
\hline Experiment name & Bias & RMSE & Correlation & Regression \\
\hline JRA55-DS & 0.290 & 1.400 & 0.9544 & $\mathrm{y}=1.204 \mathrm{x}-0.513$ \\
d4PDF-DS01 & -0.161 & 1.305 & 0.9536 & $\mathrm{y}=1.168 \mathrm{x}-0.821$ \\
d4PDF-DS02 & -0.219 & 1.331 & 0.9529 & $\mathrm{y}=1.172 \mathrm{x}-0.896$ \\
d4PDF-DS03 & -0.254 & 1.412 & 0.9530 & $\mathrm{y}=1.205 \mathrm{x}-1.060$ \\
d4PDF-DS04 & -0.328 & 1.417 & 0.9524 & $\mathrm{y}=1.198 \mathrm{x}-1.105$ \\
d4PDF-DS05 & -0.205 & 1.393 & 0.9526 & $\mathrm{y}=1.199 \mathrm{x}-0.985$ \\
d4PDF-DS06 & -0.381 & 1.416 & 0.9525 & $\mathrm{y}=1.192 \mathrm{x}-1.135$ \\
d4PDF-DS07 & -0.189 & 1.335 & 0.9534 & $\mathrm{y}=1.179 \mathrm{x}-0.891$ \\
d4PDF-DS08 & -0.630 & 1.463 & 0.9530 & $\mathrm{y}=1.176 \mathrm{x}-1.322$ \\
d4PDF-DS09 & -0.159 & 1.354 & 0.9530 & $\mathrm{y}=1.187 \mathrm{x}-0.892$ \\
d4PDF-DS10 & -0.085 & 1.346 & 0.9537 & $\mathrm{y}=1.190 \mathrm{x}-0.831$ \\
\hline
\end{tabular}

(b) Winter precipitation total $\left[\mathrm{mm} 3 \mathrm{month}^{-1}\right]$

\begin{tabular}{lcccc}
\hline Experiment name & \multicolumn{1}{c}{ Bias } & RMSE & Correlation & Regression \\
\hline JRA55-DS & 0.569 & 94.1418 & 0.8903 & $\mathrm{y}=0.836 \mathrm{x}+42.870$ \\
d4PDF-DS01 & 33.532 & 102.750 & 0.8812 & $\mathrm{y}=0.795 \mathrm{x}+93.956$ \\
d4PDF-DS02 & 45.395 & 106.265 & 0.8847 & $\mathrm{y}=0.822 \mathrm{x}+98.086$ \\
d4PDF-DS03 & 34.661 & 102.730 & 0.8841 & $\mathrm{y}=0.836 \mathrm{x}+83.237$ \\
d4PDF-DS04 & 42.936 & 104.497 & 0.8896 & $\mathrm{y}=0.865 \mathrm{x}+82.884$ \\
d4PDF-DS05 & 48.173 & 104.729 & 0.8922 & $\mathrm{y}=0.829 \mathrm{x}+98.603$ \\
d4PDF-DS06 & 33.502 & 98.5110 & 0.8961 & $\mathrm{y}=0.877 \mathrm{x}+69.874$ \\
d4PDF-DS07 & 43.378 & 105.776 & 0.8828 & $\mathrm{y}=0.795 \mathrm{x}+104.01$ \\
d4PDF-DS08 & 40.508 & 108.050 & 0.8863 & $\mathrm{y}=0.922 \mathrm{x}+63.542$ \\
d4PDF-DS09 & 60.104 & 113.289 & 0.8880 & $\mathrm{y}=0.865 \mathrm{x}+99.889$ \\
d4PDF-DS10 & 39.696 & 103.692 & 0.8844 & $\mathrm{y}=0.776 \mathrm{x}+105.76$ \\
\hline
\end{tabular}

ary conditions of d4PDF global climate simulations. This is because the JRA55-DS shows no positive biases (Fig. 3b, Table 3) and the d4PDF global climate experiment shows a positive bias of winter precipitation around Japan in comparison with Global Precipitation Climatology Project (GPCP) (Figure not shown).

Figure 4 shows horizontal distributions of TAS and precipitation biases. The horizontal patterns of TAS biases are similar between JRA55-DS and d4PDF-DSall. Both experiments show cold biases in the northeastern parts of Japan's main island and warm biases in the central and western parts of Japan. Winter precipitation is underestimated in JRA55-DS on the Sea of Japan side of central and western Japan. The same biases are found in d4PDF-DSall except for in the Kanto region. The Kanto region shows positive (negative) biases in JRA55-DS (d4PDF-DSall). The underestimation and overestimation of winter pre- cipitation on the Sea of Japan side and Pacific Ocean side, respectively, have been improved as compared with the d4PDF 20-km NHRCM experiments (Kawase et al. 2015; Kawase et al. 2016). The spatial correlation between the observed and simulated winter precipitation is higher than that in the $20-\mathrm{km}$ NHRCM (Kawase et al. 2016).

\subsection{Simulated heavy daily snowfall}

Figure 5 shows snowfall numbers on all days and the 99th percentile heavy daily snowfall in JRA55DS and d4PDF-DSall during the snowfall days. A snowfall day is defined as a day with snowfall over $1 \mathrm{~cm}$. In JRA55-DS, numbers of snowfall days are more than 1,000 in the inland areas along the Sea of Japan, while the number is less than 50 over the Pacific Ocean coasts (Fig. 5a). The d4PDF-DSall, on the other hand, shows that the number is more than 100 even over the Pacific Ocean coasts (Fig. 5d). The 
(a) Winter mean temperature [JRA55]

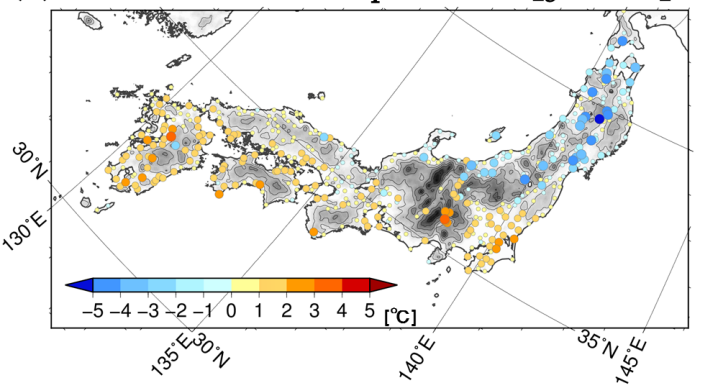

(b) Winter precipitation [JRA55]

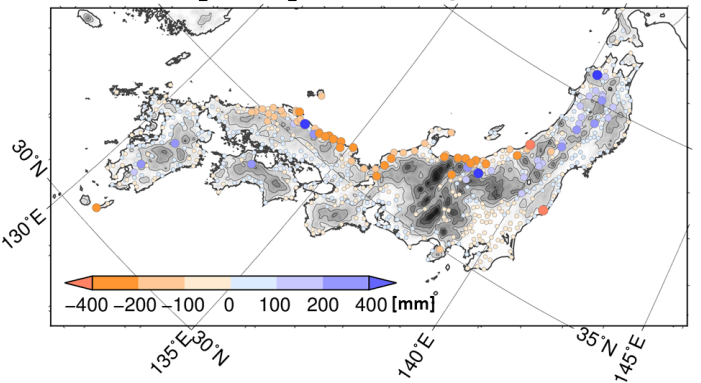

(c) Winter precipitation (ratio) [JRA55]

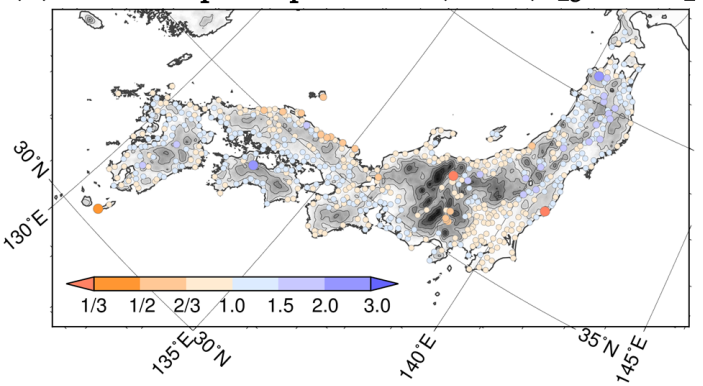

(d) Winter mean temperature [d4PDF-DSall]

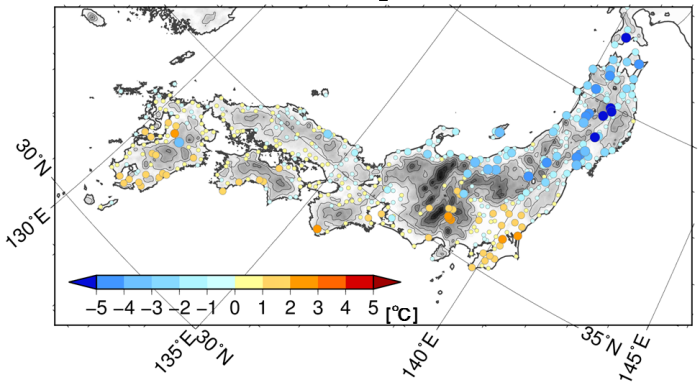

(e) Winter precipitation [d4PDF-DSall]

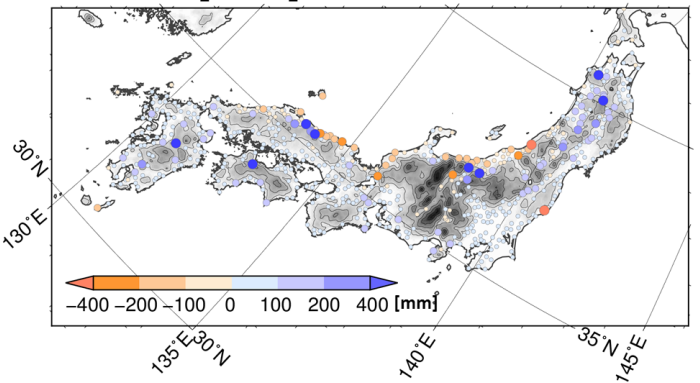

(f) Winter precipitation (ratio) [d4PDF-DSall]

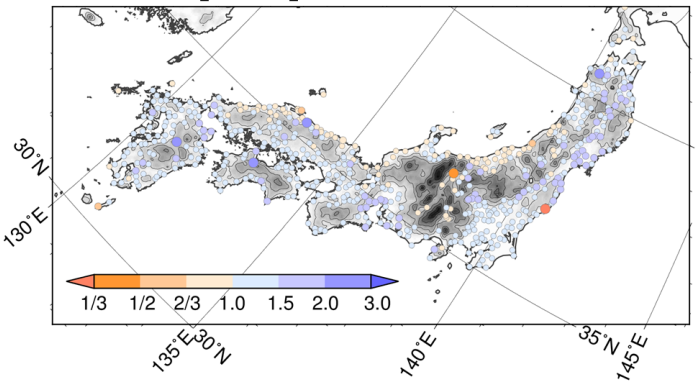

Fig. 4. Horizontal distribution of biases of the winter mean temperature and winter precipitation total simulated by $(a-c)$ JRA55-DS and (d-f) d4PDF-DSall.

99th percentile daily snowfall is over $80 \mathrm{~cm}$ only in the highest mountainous area along the Sea of Japan and is over $50 \mathrm{~cm}$ in the inland areas along the Sea of Japan and central Japan both in the JRA55-DS and the d4PDF-DS (Figs. 5b, e). However, the 99th percentile daily snowfall cannot be accurately evaluated by the JRA55-DS over the Pacific Ocean coasts because of a lack of samples, i.e., the 99th percentile value is the same as the 100th percentile value. The d4PDFDSall can evaluate the 99th percentile values in most parts of the analysis area. A lack of samples in JRA55DS restricts the comparison of 99th percentile values between JRA55-DS and d4PDF-DSall over the Kanto plain and coastal areas in western Japan. Figures 5c and $5 \mathrm{f}$ show a maximum daily snowfall simulated by JRA55-DS, i.e., 100th percentile daily snowfall, and the differences of 100th percentile daily snowfall between d4PDF-DSall and JRA55-DS. The 100th percentile snowfall exceeds $100 \mathrm{~cm}$ in the mountainous areas of central and northeastern Japan (Fig. 5c). The maximum daily snowfall in d4PDF-DSall is larger than that in JRA55-DS in most parts of the analysis area except for the inland area in northeastern Japan (Fig. 5f). Over northeastern Japan, the maximum daily snowfall depends on one extremely heavy snowfall event that occurred on December 24, 1980 due to the developing extratropical cyclone in JRA55-DS. The JMA Yamagata station, near the areas, observed 54-cm daily snowfall on that day, which is a record for heavy daily snowfall at the station since 1953 . 

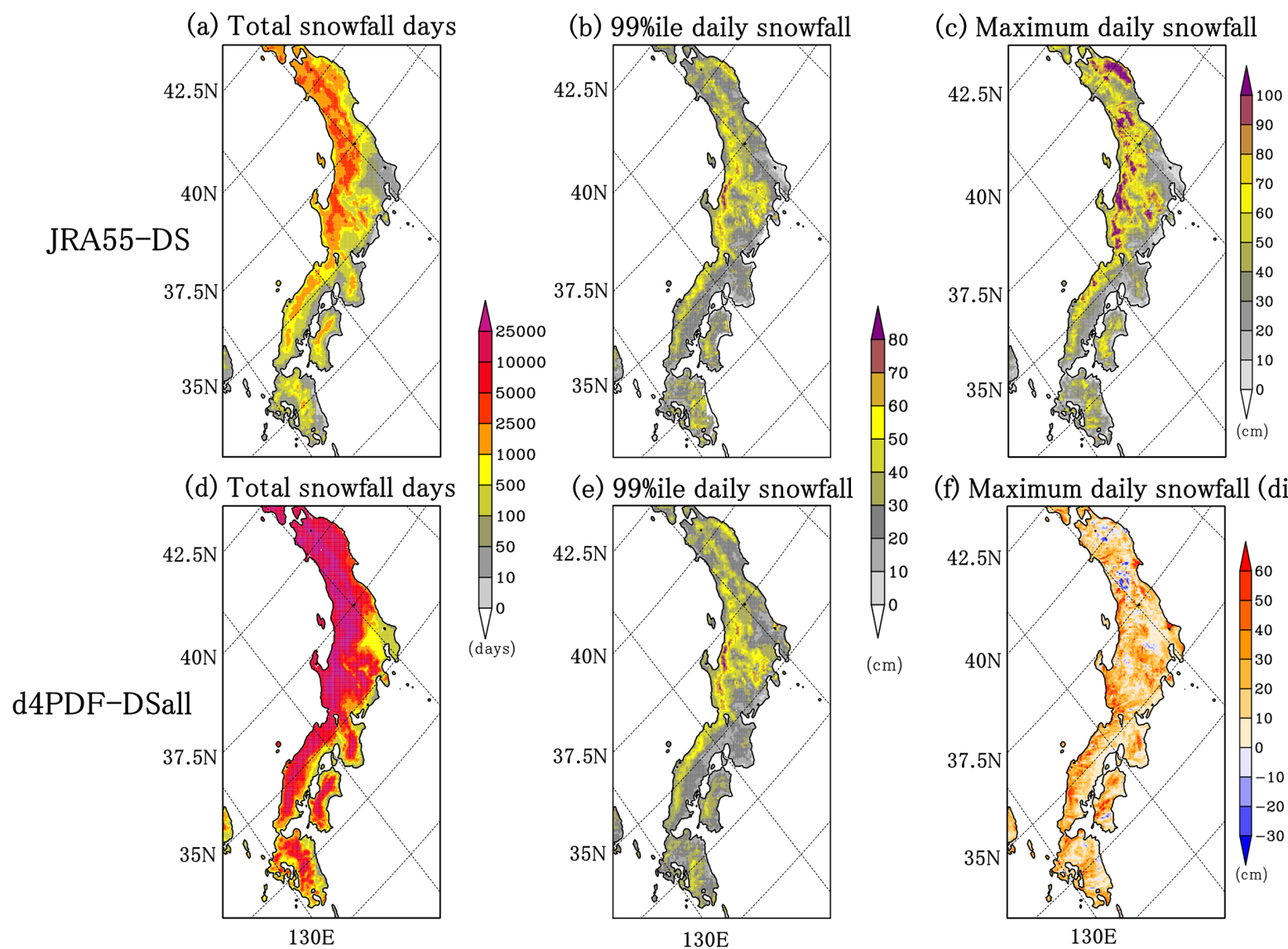

(f) Maximum daily snowfall (dif.)

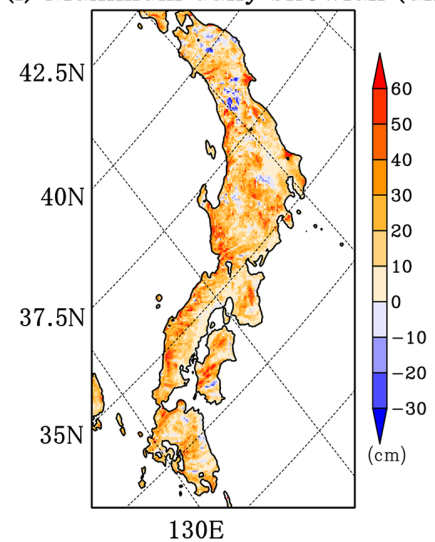

Fig. 5. (a, d) Numbers of all snowfall days and (b, e) 99th percentile heavy daily snowfall simulated by (a, b) JRA55-DS and (d, e) d4PDF-DSall. (c) Maximum daily snowfall simulated by JRA55-DS, i.e., 100th percentile daily snowfall, and (f) differences of 100th percentile daily snowfall between d4PDF-DSall and JRA55-DS. Warm color means larger snowfall in d4PDF-DSall than that in JRA55-DS.

The maximum values are not necessarily larger in d4PDF-DSall than in JRA55-DS. Note that JRA55DS and d4PDF-DSall have the biases in winter mean temperature and precipitation (Fig. 4). Cold and warm biases increase and decrease the numbers of samples, respectively. The positive precipitation bias in $\mathrm{d} 4 \mathrm{PDF}-$ DS (Fig. 4 and Table 4) can overestimate the amount of daily snowfall in the 99th percentile (Figs. 5b, c, $e, f)$.

Figure 6 shows the cumulative frequency distribution (CFD) of the daily snowfall simulated by AMeDAS, JRA55-DS, each d4PDF-DS member, and d4PDF-DSall in Tokyo, Tokamachi, and Nagoya. The locations of the stations are shown in Fig. 1b. Tokyo and Nagoya are located along the Pacific Ocean. Tokamachi, well known as a town with heavy snow covers, is located on the Sea of Japan side. The daily snowfall intensity was well simulated for Tokyo and Nagoya (Figs. 6a, c). Note that the JRA55-DS and each d4PDF-DS have 31 years, respectively. It is difficult to evaluate the extremely heavy snowfall occurring every 10 years. The daily snowfall is underestimated in all intensities at Tokamachi (Fig. 6b). The winter precipitation is a little underestimated by NHRCM in Tokamachi (Fig. 3), which cannot be explained by only the precipitation bias. The daily snowfall is defined as a sum of the difference in hourly snow depth as calculated by the iSiB land surface model. The iSiB may underestimate the hourly increment of snow depth in Tokamachi, where the climatology of annual maximum snow depth exceeds $200 \mathrm{~cm}$. Figure 6 hints that the 99th and 100th percentile values in Fig. 5 are underestimated over the enormous snowfall areas.

The CFD of daily snowfall intensity in JRA55-DS 

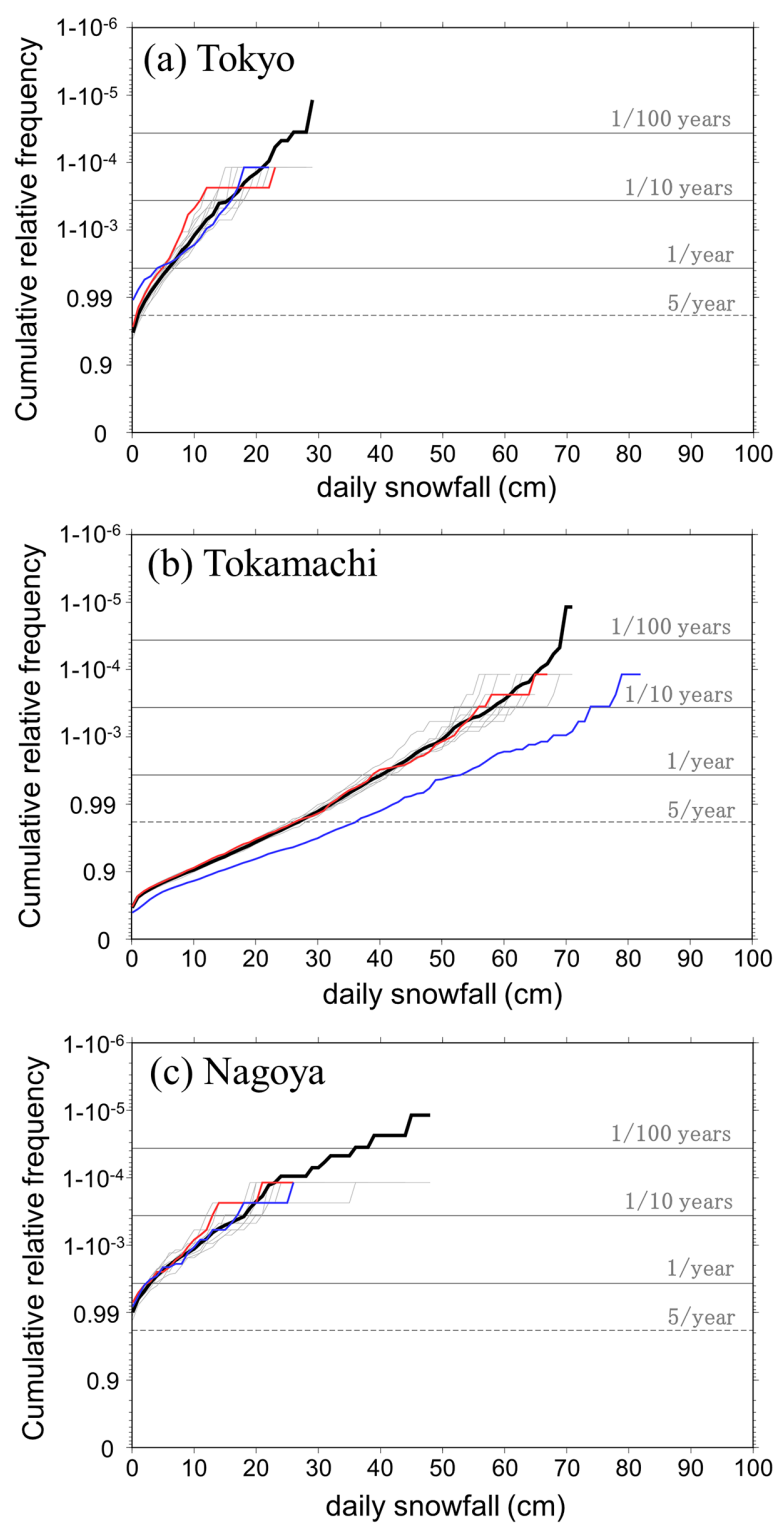

Fig. 6. Cumulative frequency distribution of daily snowfall at (a) Tokyo, (b) Tokamachi, and (c) Nagoya. The locations of stations are shown in Fig. 1b. Thick blue, thick red, thin gray and thick black lines represent AMeDAS, JRA55DS, each d4PDF-DS, and d4PDF-DSall, respectively.

is almost in the range of those of d4PDF-DS ensemble members. The frequency of heavy daily snowfall occurring less than approximately once every 30 years cannot be assessed by JRA55-DS and each d4PDF-DS member because they have only 31-year simulations.
In contrast, d4PDF-DSall, which includes 310-year simulations, enables us to evaluate infrequent heavy daily snowfall.

3.3 Synoptic conditions in heavy daily snowfall events Composite analyses were conducted using the top 30 heavy daily snowfall events in d4PDF-DSall at the three stations shown in Fig. 1. Figure 7 illustrates the composites of daily snowfall, rainfall, SLP, air temperature at $925 \mathrm{hPa}$, and geopotential height at 925 $\mathrm{hPa}$. Here, snowfall is the sum of solid precipitation, i.e., snow and graupel, as calculated by the microphysics and cumulus parameterization schemes. A unit of snowfall and rainfall is $\mathrm{mm} \mathrm{day}^{-1}$, which differs from the units in Figs. 5 and 6. Note that the larger amount of rainfall or snowfall is illustrated in the case of the daily precipitation including both rainfall and snowfall. For Tokyo, low SLP appears over south of Japan (Fig. 7a), indicating a southern coastal extratropical cyclone. This SLP pattern is a typical pattern that causes snowfall around Tokyo. Lower SLP is found over the eastern part of the Japanese island, which is known as cold air damming (Bailey et al. 2003; Fujibe 2001). Tokyo is located at a boundary between snowfall and rainfall. The mean air temperature around Tokyo is $0^{\circ} \mathrm{C}$ to $-2^{\circ} \mathrm{C}$ at $925 \mathrm{hPa}$ (Fig. $7 \mathrm{~d}$ ).

On the other hand, the composite of heavy daily snowfall days at Tokamachi shows a typical SLP pattern during cold air outbreaks (Fig. 7b), i.e., a zonal pressure gradient over Japan. The direction of isobars is from northwest to southeast. Large snowfalls are found around the mountainous areas on the Sea of Japan side.

Nagoya is located on the Pacific Ocean side of Japan (Fig. 1b). The composite, however, shows an SLP pattern similar to that of Tokamachi (Fig. 7c). The pressure gradient at Nagoya is the largest and the air temperature at $925 \mathrm{hPa}$ is lowest among three stations (Fig. 7f). Fujiyoshi et al. (1996) previously pointed out that snowfall sometimes occurs at Nagoya due to cold air outbreaks. Moreover, a clear snowfall band that extends to central Japan, the so-called JPCZ, is found over the western part of the Sea of Japan (Fig. 7c). Therefore, a strong cold air outbreak and the JPCZ are required to induce heavy daily snowfall at Nagoya.

JRA55-DS and d4PDF-DSall include 31 and 310 years, respectively, which suggests that d4PDF-DSall can simulate less frequent and heavier daily snowfall events than the JRA55-DS can. We compare composites of the top 30 heavy daily snowfall events calculated by JRA55-DS and d4PDF-DSall to investigate 
(a) Tokyo

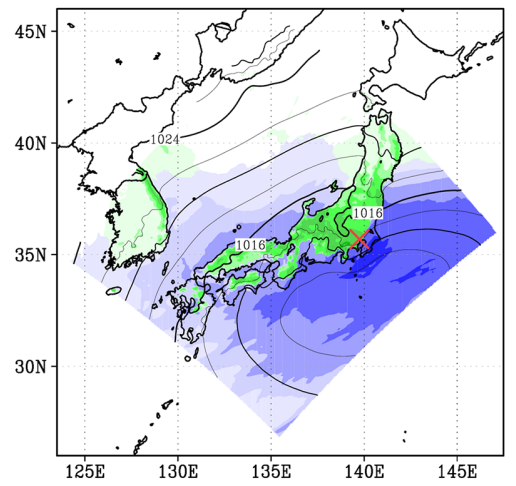

(d) Tokyo

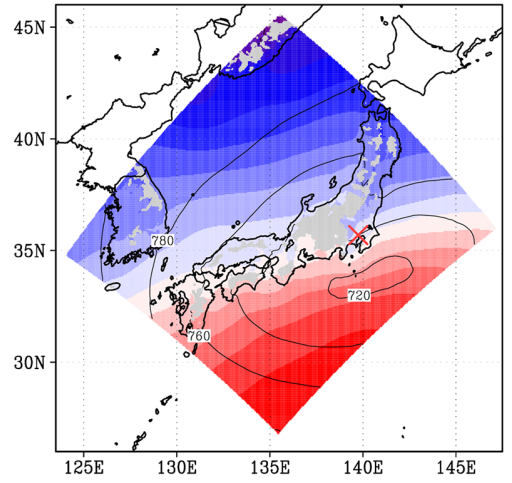

(b) Tokamachi

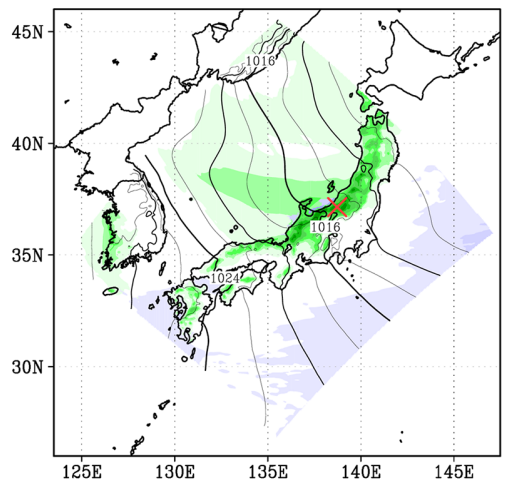

(e) Tokamachi

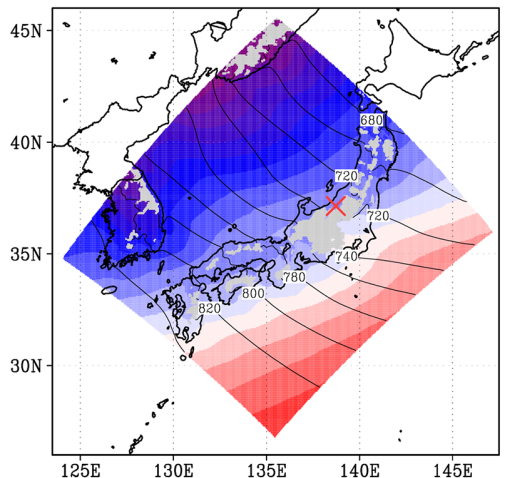

(c) Nagoya

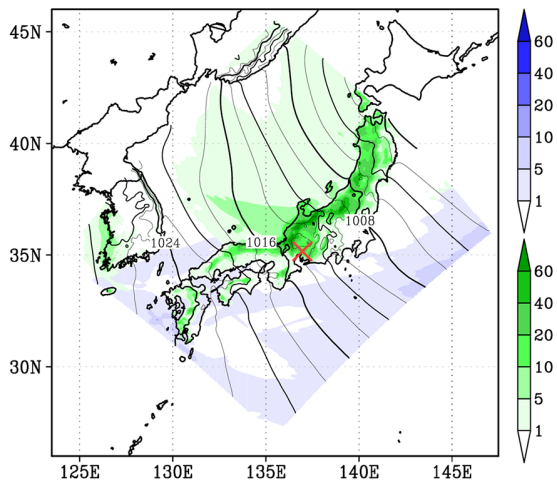

(f) Nagoya

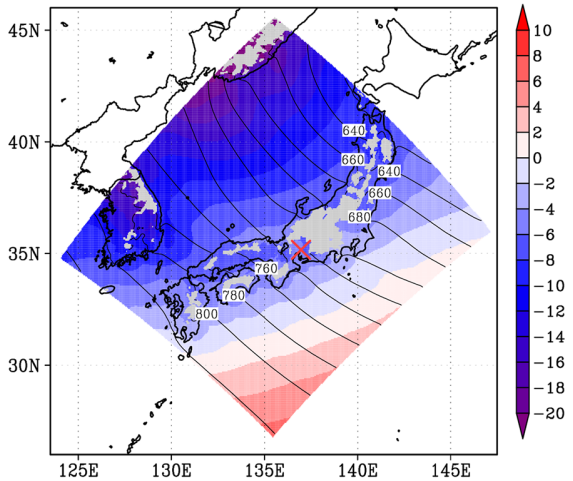

Fig. 7. Composite of top 30 heavy daily snowfall events simulated by d4PDF-DS. (a-c) Daily snowfall, rainfall, and SLP. Green and blue shadings represent daily snowfall and rainfall, respectively. The unit of snowfall and rainfall is $\mathrm{mm} \mathrm{day}^{-1}$. Contours represent the SLP. $(\mathrm{d}-\mathrm{f})$ Air temperature (shading) and geopotential height (contour) at $925 \mathrm{hPa}$. Red cross marks represent the locations of (a, d) Tokyo, (b, e) Tokamachi, and (c, f) Nagoya.

the synoptic conditions that produce much heavier snowfall events at each station (Figs. 8, 9).

A low SLP anomaly appears south of central Japan, indicating the enhancement of the southern coastal extratropical cyclone during heavier snowfall events in Tokyo (Fig. 8a). The intrusion of a high SLP anomaly appearing over Kanto and northwestern Japan shows strengthened cold air damming. Over the Kanto plain, the difference in air temperatures at $925 \mathrm{hPa}$ is quite small, meaning that heavier snowfall in $\mathrm{d} 4 \mathrm{PDF}-$ DS occurs at approximately $0^{\circ} \mathrm{C}$ to $-2^{\circ} \mathrm{C}$, which is similar to that in JRA55-DS (Fig. 8d). By contrast, the air temperature is higher over the Pacific Ocean and the Sea of Japan. Some mechanisms of atmospheric cooling have been pointed out over the Kanto plain, e.g., evaporative cooling, melting cooling, and cold air damming (Fujibe 2001). These mechanisms can maintain a cold pool in the Kanto plain. Figure 9 shows the differences in the SST and the vertical temperature gradient from $925 \mathrm{hPa}$ to $500 \mathrm{hPa}$ (hereafter, T925T500), which correspond to static stability. During heavy snowfall events in Tokyo, the differences of the SST around Japan and the T925-T500 around Tokyo are insignificant (Fig. 9a).

The heavier daily snowfall events at Tokamachi show a larger pressure gradient from southwest to northeast, which is relatively smaller than that in Tokyo (Figs. 8b, e). The SST of the Sea of Japan is warmer in the d4PDF-DSall during heavy snowfall events in Tokamachi (Fig. 9b).

There are obvious SLP and temperature differences in heavy daily snowfall events in Nagoya (Figs. 8c, f). A large pressure gradient from southwest to northeast, i.e., stronger cold air outbreaks, causes heavier snowfall around Nagoya in colder situations. Moreover, the snowfall and SLP anomaly indicate an enhancement of the JPCZ over the western part of the Sea of Japan. A warm SST anomaly is also found in the Sea of 
(a) Tokyo

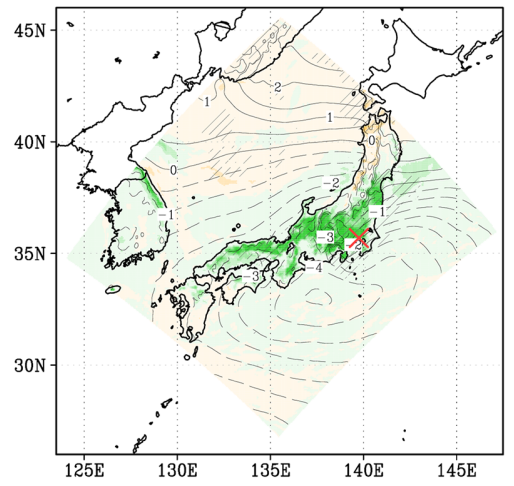

(d) Tokyo

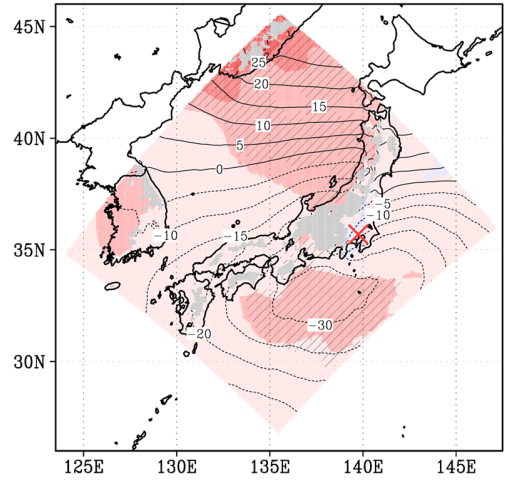

(b) Tokamachi

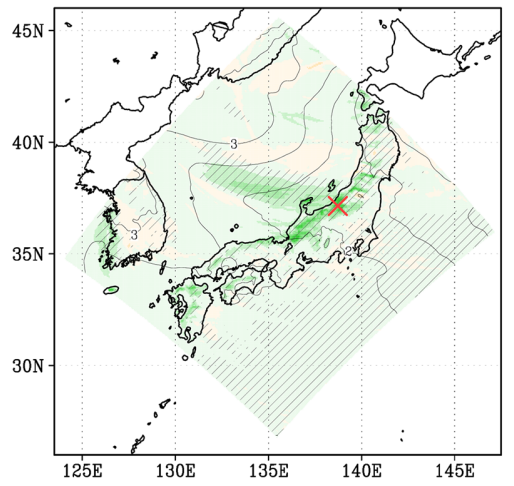

(e) Tokamachi

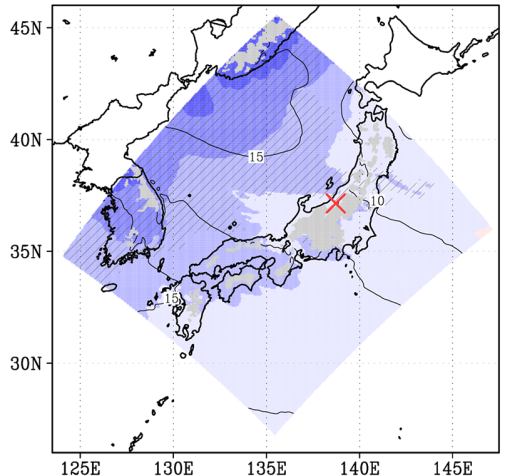

(c) Nagoya

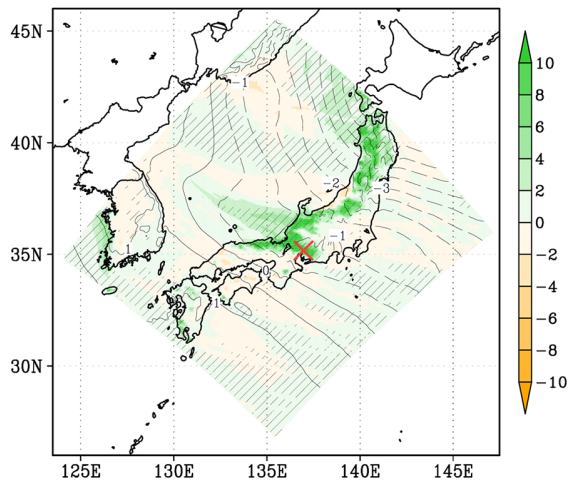

(f) Nagoya

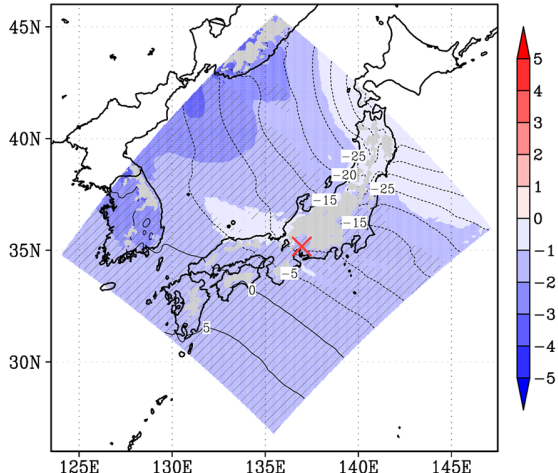

Fig. 8. Differences in composites of top 30 heavy daily snowfall events between d4PDF-DS and JRA55-DS. (a-c) Snowfall (shading) and SLP (contour). Green shading indicates that snowfall in d4PDF-DSall is larger than that in JRA55-DS. Solid (broken) lines indicate that the SLP in d4PDF-DSall is higher (lower) than that in JRA55DS. (d-f) Air temperature (shading) and geopotential height (contour) at $925 \mathrm{hPa}$. Hatched areas represent significant changes in $(\mathrm{a}-\mathrm{c})$ snowfall and $(\mathrm{d}-\mathrm{f})$ air temperature at the $95 \%$ confidence interval $(\mathrm{CI})$, according to the Mann-Whitney U-test. Red cross marks represent the locations of (a, d) Tokyo, (b, e) Tokamachi, and (c, f) Nagoya.

(a) Tokyo

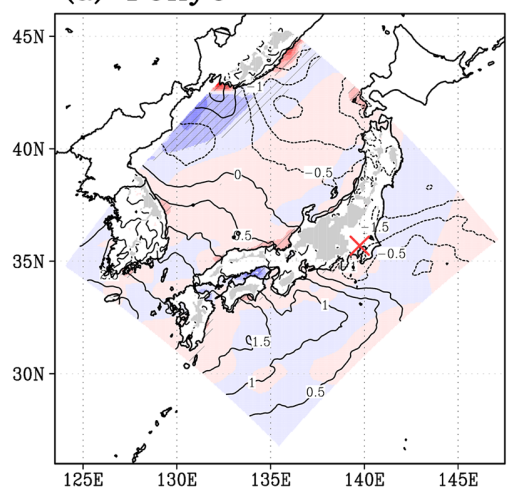

(b) Tokamachi

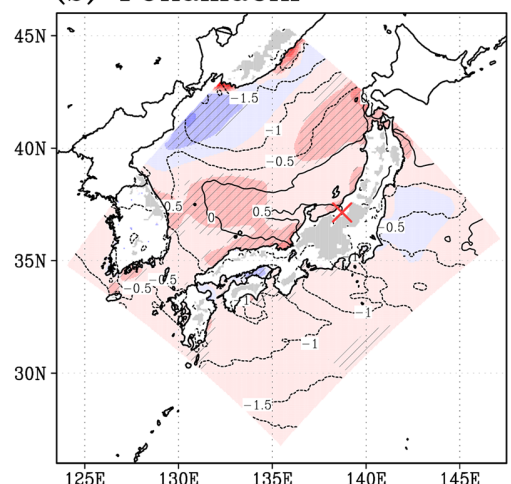

(c) Nagoya

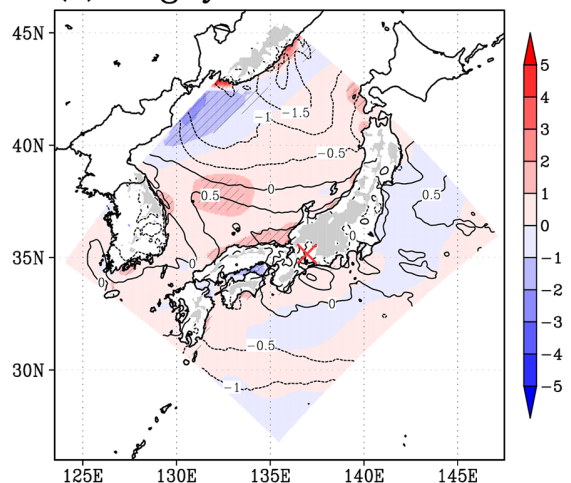

Fig. 9. Same as Fig. 8, but differences of SST (shading) and vertical temperature gradient between $925 \mathrm{hPa}$ and $500 \mathrm{hPa}$ (contour). Hatched areas represent significant changes in SST at the $95 \% \mathrm{CI}$, according to the Mann-Whitney $U$-test. Red cross marks represent the locations of (a) Tokyo, (b) Tokamachi, and (c) Nagoya. 
Japan. The positive T925-T500 area, meaning less static stability, appears along the JPCZ (Fig. 9c). Therefore, a stronger cold air outbreak and enhanced JPCZ can produce heavier snowfall around Nagoya.

\section{Geographical distribution of SLP patterns causing heavy daily snowfall}

\subsection{All snowfall events}

Two major factors cause heavy daily snowfall in central Japan - the cold air outbreak and the southern coastal extratropical cyclone (Ando and Ueno 2015). As stated in Section 3, heavy snowfall is brought about by cold air outbreaks at Tokamachi and Nagoya, and by the southern coastal extratropical cyclone at Tokyo (Fig. 8). In some areas of Japan, heavy daily snowfall events occur in multiple synoptic conditions. In our simulation, approximately $75 \%$ and $25 \%$ of heavy snowfall events in the city of Nagano, which is located in a small basin in central Japan, correspond to cold air outbreaks and southern coastal extratropical cyclones, respectively. Here, we classify all snowfall events based on SLP patterns. Our methodology for classification has been explained in Section 2. Note that the analysis area is smaller than the model domain because our classification of pressure patterns needs the model grids which are meridionally and zonally $\pm 3^{\circ}$ away from the targeted grid (See Section 2.2).

The 31-years mean annual total number of snowfall days is more than 90 in mountainous areas of northeastern and central Japan (Fig. 10a), while the number of days is fewer than 10 in the Pacific coastal areas in central and western Japan. Most snowfall days are classified as having the WhEl pattern (Fig. 10b). The frequency of snowfall caused by the $\mathrm{NhSl}$ pattern, i.e., a southern coastal extratropical cyclone, is relatively low over Japan (Fig. 10c). The number of other patterns, such as extratropical cyclones passing over the Sea of Japan (Chen et al. 1991; Adachi and Kimura 2007), is much smaller than the numbers of NhSl and WhEl patterns (Fig. 10d). Note that the number of snowfall days in northeastern (western) Japan can be overestimated (underestimated), since d4PDF-DS has cold (warm) biases in northeastern (western) Japan (Fig. 4).

Figures $11 \mathrm{a}$ and $11 \mathrm{~b}$ show the relative frequency of snowfall days in each pressure pattern as simulated by d4PDF-DS01. About $70 \%$ of snowfall occurs under the WhEl pattern on the Sea of Japan side (Fig. 11a). It is noteworthy that more than $80 \%$ of snowfall occurs under the WhEl pattern in the Tokai area, where Nagoya is located. In the inland area of the Kanto region, more than $70 \%$ of snowfall occurs under the NhSl pattern, i.e., most snowfall is induced by southern coastal extratropical cyclones (Fig. 11b). Snowfall also occurs under the NhSl pattern in the east of the Kii Peninsula, the east of Shikoku, and Sanyo. Even on the Pacific Ocean side, half of the total snowfall occurs under the WhEl pattern, except for inland areas of the Kanto region. (a) Total number of days

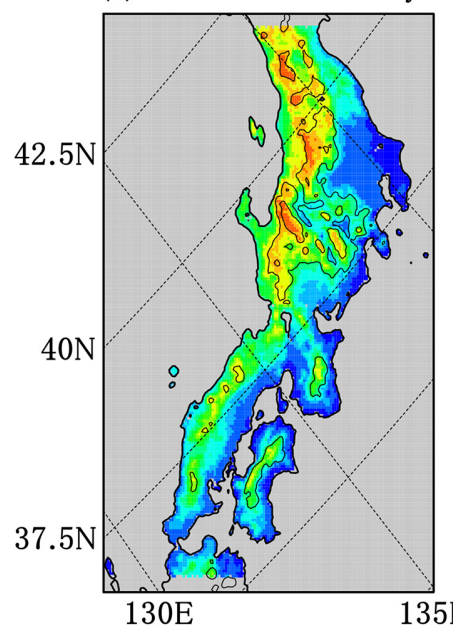

\section{(b) WhEl pattern}

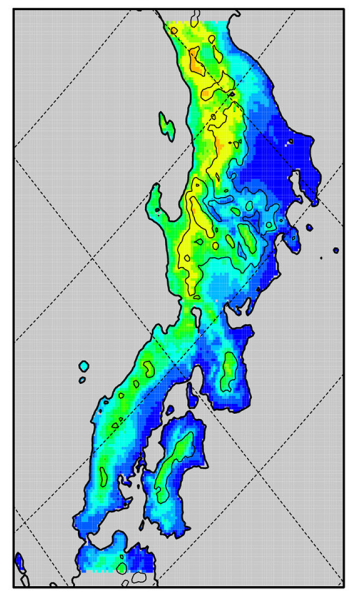

(c) NhSl pattern

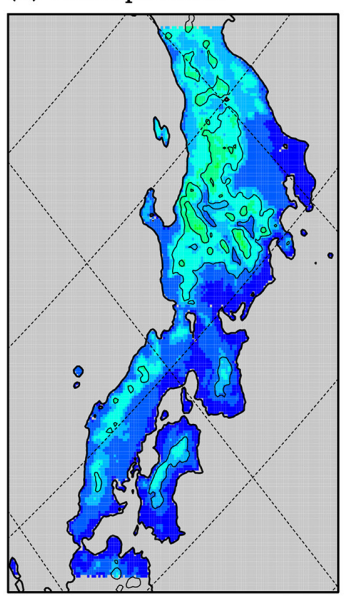

(d) Other pattern

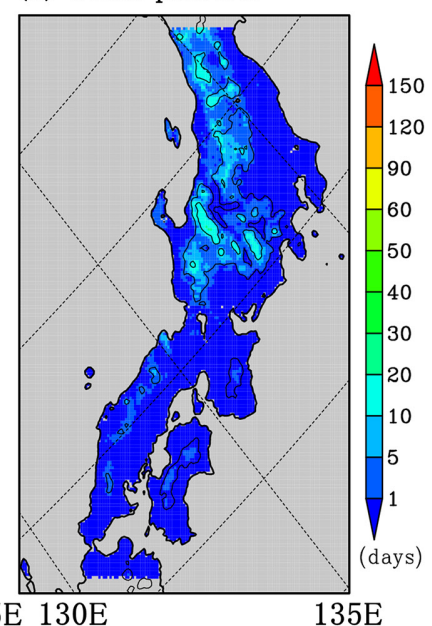

Fig. 10. Number of days with snowfall exceeding $1 \mathrm{~cm}$ day $^{-1}$ simulated by d4PDF-DS01. (a) Total number, (b) number of WhEl patterns, (c) number of NhSl patterns, and (d) number of other patterns. Contours represent the terrain height and the contour interval is $1,000 \mathrm{~m}$. 
(a) d4PDS-DS01 WhEl

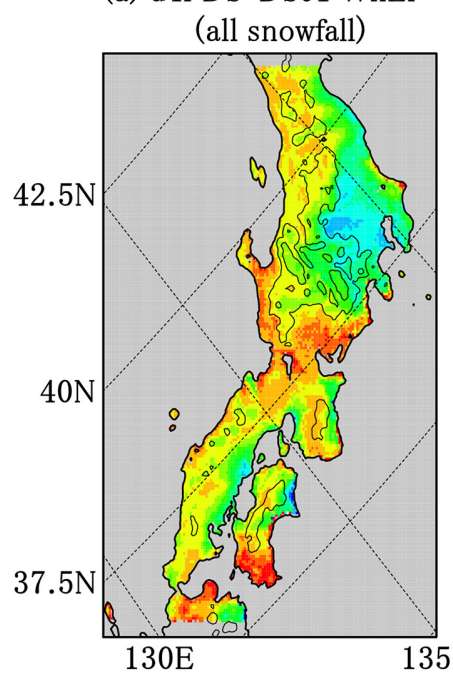

(b) d4PDS-DS01 NhSl (all snowfall)

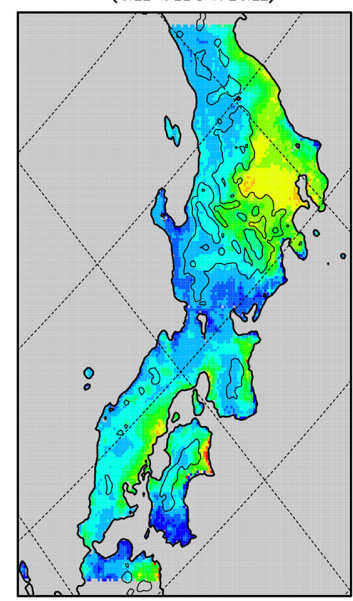

(c) d4PDS-DSall WhEl

(top 30 heavy snowfall)

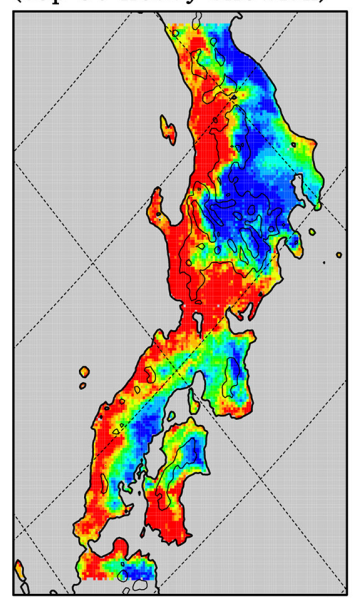

(d) d4PDS-DSall NhSl

(top 30 heavy snowfall)

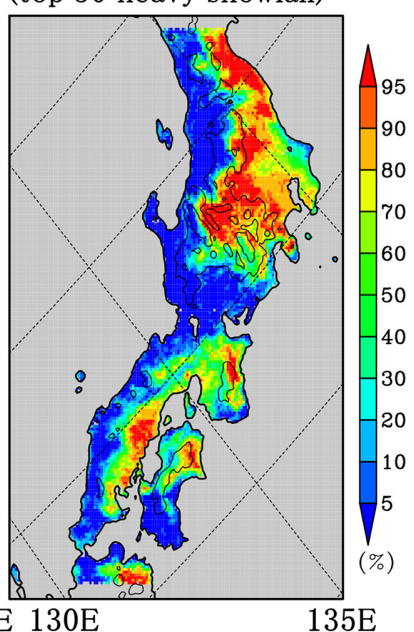

Fig. 11. Percentage of SLP pattern occurrences. (a) WhEl patterns and (b) NhSl patterns in all snowfall events in d4PDF-DS01. (c) WhEl patterns and (d) NhSl patterns in the top 30 heavy daily snowfall events of d4PDFDSall. Contours represent the terrain height, and the contour interval is $1,000 \mathrm{~m}$.

\subsection{Top 30 heavy daily snowfall events}

The geographical boundaries of $\mathrm{NhSl}$ and WhEl patterns in the top 30 heavy daily snowfall events are much clearer than those in all snowfall events (Figs. $11 \mathrm{a}, \mathrm{b})$. Most heavy daily snowfall events occur under the WhEl pattern along the Sea of Japan. The WhEl pattern also frequently induces heavy daily snowfall events in the Tokai region and the western part of the Shikoku region. On the other hand, more than $80 \%$ of heavy daily snowfall events occur under the $\mathrm{NhSl}$ pattern in the Kanto region, the eastern part of the Kii Peninsula, and the eastern part of Shikoku (Fig. 11d). Over the Kii peninsula, snowfall frequently occurs under the WhEl pattern (Figs. 11a, b), while the extremely heavy snowfall occurs under the $\mathrm{NhSl}$ pattern (Figs. 11c, d). Over the inland areas in central Japan and the Pacific Ocean side in northeastern Japan, snowfall occurs under both $\mathrm{WhEl}$ and $\mathrm{NhSl}$ patterns, while most of the extremely heavy snowfall events are brought by the NhSl pattern, i.e., southern coastal extratropical cyclones. It is noteworthy that heavy daily snowfall frequently occurs under the $\mathrm{WhEl}$ pattern in the eastern part of the Kanto plain. In this region, southern coastal extratropical cyclones mainly cause rainfall because relatively warm air flows into this region from the Pacific Ocean. A local convergence line generated under the $\mathrm{WhEl}$ pattern brings relatively heavy daily snowfall over the eastern part of the Kanto plain (Figure not shown).
Figure 12a shows the mean TAS in the top 30 heavy daily snowfall events. The mean TAS is around $0^{\circ} \mathrm{C}$ over the Kanto region, while the TAS is less than $-5^{\circ} \mathrm{C}$ over inland and mountainous areas. The mean TAS is less than $-10^{\circ} \mathrm{C}$ over the high mountains in central Japan. Figure $12 \mathrm{~b}$ shows the months that account for the largest fraction of top 30 heavy daily snowfall events in each grid. Heavy daily snowfall occurs from December to January along the Sea of Japan, where the WhEl pattern frequently brings heavy daily snowfalls (Fig. 11c). By contrast, heavy daily snowfall occurs from January to February on the Pacific Ocean side of Japan, where the NhSl pattern, i.e., extratropical cyclone, causes heavy daily snowfall events (Fig. 11d). In the Tokai region where heavy daily snowfall is brought under the WhEl pattern, heavy daily snowfall mainly occurs in January. Heavy daily snowfall events appear in November and March over the mountain ranges in central and northeastern Japan. Especially, the heavy snowfall occurs in November (March) over the western (eastern) side of the mountain ranges under the $\mathrm{WhEl}(\mathrm{NhSl})$ pattern.

The sensitivity analyses were conducted using thresholds of $2.5 \mathrm{hPa}$ and $7.5 \mathrm{hPa}$. The differences between the thresholds of $5 \mathrm{hPa}$ and $7.5 \mathrm{hPa}$ are quite small, both in all the cases (Fig. 10) and also in the top 30 heavy snowfall cases (Fig. 11). The numbers of $\mathrm{NhSl}$ and WhEl patterns increase and decrease, respectively, when the threshold of $2.5 \mathrm{hPa}$ is applied. 
(a) Mean daily surface air temperature

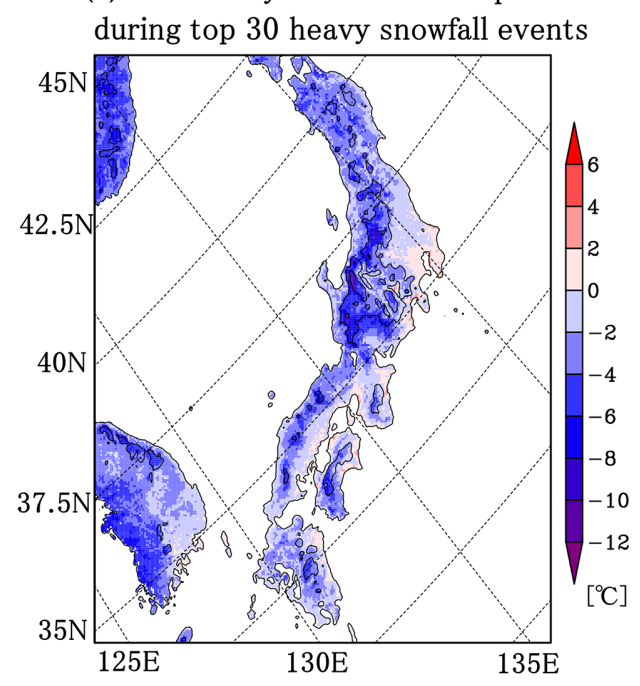

(b) Month having largest number of top 30 heavy snowfall events

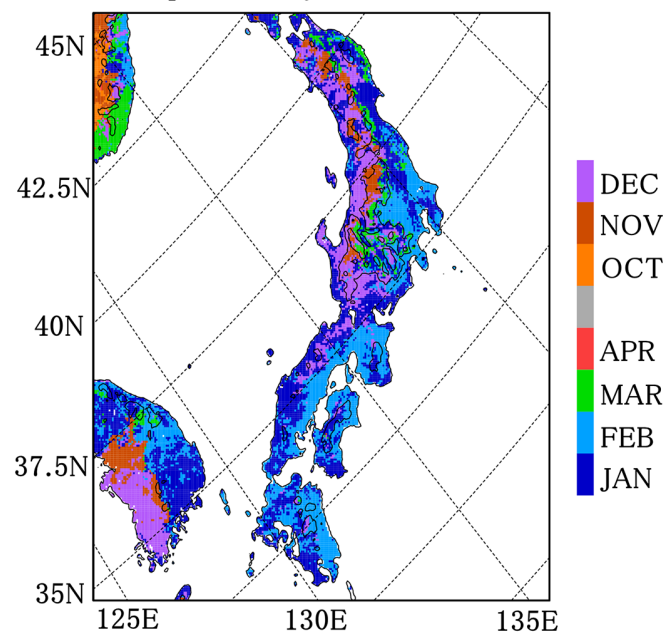

Fig. 12. (a) Mean surface air temperature and (b) month having the largest number of events in the top 30 heavy daily snowfall events of d4PDF-DSall. Contours represent the terrain height, and the contour interval is $1,000 \mathrm{~m}$.

The analyses using threshold of $2.5 \mathrm{hPa}$ and $7.5 \mathrm{hPa}$ show the same characteristics of horizontal pattern and same differences of ratio between all cases (Fig. 10) and extreme cases (Fig. 11). These results indicate that our results are not influenced by the threshold of pressure gradients around $5 \mathrm{hPa}$.

Saturated water vapor pressure depends on temperature, which is known as the Clausius-Clapeyron relation. Warmer SSTs supply more water vapor to the lower atmosphere. Generally, heavy precipitation occurs more frequently in warmer conditions. A surface air temperature of $0^{\circ} \mathrm{C}$ is the highest temperature allowing snowfall, and saturated water vapor at $0^{\circ} \mathrm{C}$ is larger than that below $0^{\circ} \mathrm{C}$. On the other hand, the mean TAS in heavy daily snowfall events is much lower than $0^{\circ} \mathrm{C}$, especially in the inland areas along the Sea of Japan (Fig. 12a). In these regions, the occurrence of heavy daily snowfall relates to the synoptic conditions of winter. Strong cold air outbreaks and warm SSTs in early winter are important for bringing a lot of snowfall over the inland areas along the Sea of Japan (Fig. 12b).

Analyzing the d4PDF regional climate experiments with $20-\mathrm{km}$ grid spacing, Kawase et al. (2016) suggested that the frequency of heavy daily snowfall could increase over the mountainous areas of central Japan in the future climate. They speculated that the enhancements of the JPCZ and topographic upward flow due to moistening could cause heavy daily snowfalls in warmer climates. Our results suggest that, in the current climate, the winter temperature is too low to cause the heaviest daily snowfall over high mountainous areas. On the Pacific Ocean side, including in the Kanto plain, the surface air temperature during heavy daily snowfall events is high enough to cause the heaviest snowfall in the present climate. The amount and frequency of the heavy daily snowfall would decrease in the warmer climate in the future.

\section{Summary}

We clarified the characteristics of extremely heavy daily snowfalls in western, central, and northeastern Japan, analyzing high-resolution regional climate simulations with a $5-\mathrm{km}$ grid spacing based on JRA-55 and d4PDF. JRA55-DS and d4PDF-DS well simulate the observed winter TAS, while both experiments have cold biases of around $0^{\circ} \mathrm{C}$. Both experiments show cold biases in northeastern Japan and warm biases in central and western Japan. The winter precipitation total is also well simulated by both experiments in ranges of less than $400 \mathrm{~mm}$. The reproducibility of winter precipitation in d4PDF-DS was better than that in the d4PDF 20-km NHRCM.

Ensemble experiments using d4PDF enabled us to evaluate heavy snowfall events more accurately than did those with JRA-55. Composite analyses of the top 30 heavy daily snowfall events in d4PDF-DSall show that low SLP appears over the Pacific Ocean south 
of the Kanto region, meaning southern coastal extratropical cyclones, when heavy daily snowfall events happen in Tokyo located along the Pacific Ocean. A comparison of JRA55-DS and d4PDF-DSall shows that more developed southern coastal extratropical cyclones and cold air damming could cause heavier snowfall events in Tokyo. On the other hand, the SLP shows strong cold air outbreaks due to winter monsoons when the heaviest snowfall events occur at Tokamachi located on the Sea of Japan side. Nagoya is located on Japan's Pacific Ocean side, while heavy daily snowfall events occur with strong cold air outbreaks. Stronger cold air outbreaks and enhanced JPCZ have the ability to produce much heavier snowfall around Nagoya.

The NHRCM with 5-km grid spacing resolves the complexity of the Japanese mountains, which can clarify the geographical distribution of SLP patterns that cause heavy daily snowfall. We classified the SLP patterns in all snowfall events in each model grid. The WhEl pattern means cold air outbreaks due to winter monsoons, and the NhSl pattern means southern coastal extratropical cyclones. Snowfall mainly occurs under the WhEl pattern on the Sea of Japan side, Tokai, and the western part of Shikoku; it occurs under the NhSl pattern in Kanto and the eastern part of Shikoku regions. The top 30 heavy daily snowfall events show the geographical boundaries of $\mathrm{NhSl}$ and WhEl patterns more clearly than do all snowfall events. Heavy daily snowfall events occur in December and January on the Sea of Japan side, in January and February on the Pacific Ocean side, and in November and March in the high mountainous areas of central and northeastern Japan. The mean TAS in heavy daily snowfall events is approximately $0^{\circ} \mathrm{C}$ on the Kanto plain, while it is much less than $0^{\circ} \mathrm{C}$ in the high mountainous areas in central Japan. In the high mountainous areas, the occurrence of heavy daily snowfall is strongly related to the atmospheric and oceanic conditions from late fall to early spring. Strong cold air outbreaks and warm SST in early winter bring a lot of snowfall over the high mountainous areas of central Japan.

Our results support the previous studies showing horizontal boundaries of SLP patterns causing snowfall based on the observational dataset (Ando and Ueno 2015; Suda and Ueno 2014; Fujiyoshi et al. 1996; Wakisaka 1986). We added the new findings about the horizontal distribution of extremely heavy daily snowfall and detailed horizontal boundary of all snowfall and heavy snowfall in each pressure pattern.

In this study, we conducted regional climate ex- periments with $5-\mathrm{km}$ grid spacing, which resolved Japanese complex topographies. The 5-km experiments well reproduced the winter precipitation rather than the experiments with $20-\mathrm{km}$ grid spacing (Kawase et al. 2016) and enabled us to classify the pressure-pattern-occurring heavy daily snowfall in each region. In addition, the large number of ensemble experiments simulated much heavier daily snowfall events and clarified the pressure patterns causing the heavier snowfall events in each region, as discussed in Sections 3 and 4.

The spatial resolution of $5 \mathrm{~km}$ was, however, insufficient to fully resolve the snowfall process in the high mountainous areas. The precipitation processes were calculated by both microphysics and convective cumulus parameterization in the $5-\mathrm{km}$ experiments. The $5-\mathrm{km}$ model tends to overestimate the annual maximum snow depth in the high mountainous areas, which results from overestimation of winter precipitation. A higher-resolution model with $2-\mathrm{km}$ grid spacing, so-called cloud-resolving or convectionpermitting model, would improve the overestimation of winter precipitation (Figure not shown). In the next step, the cloud-resolving model and ensemble experiments are needed to accurately simulate the heavy daily snowfall in Japan's complex mountains.

JRA55-DS and d4PDF-DS have some biases in winter temperature and precipitation. The amounts of heavy precipitation and number of snowfall days may be influenced by these model biases. However, these biases have limited impact on the results of composite analyses and SLP classifications of heavy snowfall events, since the heavy snowfall events in each region are mainly controlled by typical SLP patterns in winter rather than by the winter mean temperature. Although any regional climate models have some biases, our results indicate that heavy snowfall can occur in any regions in Japan, and the synoptic conditions causing heavy snowfall strongly depend on these regions. We hope our results play a role in formation of adaptation strategies for local governments on the extremely heavy snowfall, not only in the frequent-snowfall areas, such as the Sea of Japan side, but also in the infrequent snowfall areas, such as the Pacific Ocean side.

Finally, our results suggest that future changes in heavy daily snowfall due to global warming will be different in each region since the synoptic conditions causing heavy daily snowfall vary depending on the region in Japan. To assess future changes in heavy daily snowfall, analyses focusing on the mechanisms that cause heavy daily snowfall are required. Since 
the horizontal resolution with $20 \mathrm{~km}$ in the study by Kawase et al. (2016) is not enough to classify the pressure-pattern-occurring heavy daily snowfall in each region, higher-resolution simulation, such as the $5-\mathrm{km}$ simulations in this study, will be needed. Comparison between present and future climate simulations with higher-resolution and ensemble experiments will clarify the future changes in heavy snowfall that cause snow disasters under each synoptic condition.

\section{Acknowledgments}

We thank two reviewers for their useful comments and suggestions. This research was supported by the Social Implementation Program on Climate Change Adaptation Technology (SI-CAT) of MEXT, JAPAN. The Earth Simulator was used in this study as an "Estimation of Spatial and Temporal Patterns in Snow Depth by using Dynamic Downscaling Approach with NHRCM in central Japan" of JAMSTEC. This study was partly supported by JSPS KAKENHI Grant Number 26750111.

\section{References}

Adachi, S., and F. Kimura, 2007: A 36-year climatology of surface cyclogenesis in East Asia using high-resolution reanalysis data. SOLA, 3, 113-116.

Akiyama, T., 1981: Time and spatial variations of heavy snowfalls in the Japan Sea coastal region. Part 1. Principal time and space variations of precipitation described by EOF. J. Meteor. Soc. Japan, 59, 578-590.

Ando, N., and K. Ueno, 2015: Occurrence tendency of heavy rainfall or snowfall in the inland district of Japan in winter. Seppyo, 77, 397-410 (in Japanese with English abstract).

Aoyagi, T., and N. Seino, 2011: A square prism urban canopy scheme for the NHM and its evaluation on summer conditions in the Tokyo metropolitan area, Japan. J. Appl. Meteor. Climatol., 50, 1476-1496.

Araki, K., and M. Murakami, 2015: Numerical simulation of heavy snowfall and the potential role of ice nuclei in cloud formation and precipitation development. CAS/ JSC WGNE Res. Activ. Atmos. Oceanic Modell., 45, 4.03-4.04.

Araki, K., 2016: Influence of cloud microphysics scheme and ice nuclei on forecasting a heavy snowfall event in Japan associated with the "South-Coast Cyclones". CAS/JSC WGNE Res. Activ. Atmos. Oceanic Modell., 46, 4.03-4.04.

Bailey, C. M., G. Hartfield, G. M. Lackmann, K. Keeter, and S. Sharp, 2003: An objective climatology, classification scheme, and assessment of sensible weather impacts for Appalachian cold-air damming. Wea. Forecasting, 18, 641-661.

Chen, S.-J., Y.-H. Kuo, P.-Z. Zhang, and Q.-F. Bai, 1991:
Synoptic climatology of cyclogenesis over East Asia, 1958-1987. Mon. Wea. Rev., 119, 1407-1418.

Eito, H., T. Kato, M. Yoshizaki, and A. Adachi, 2005: Numerical simulation of the quasi-stationary snowband observed over the southern coastal area of the Sea of Japan on 16 January 2001. J. Meteor. Soc. Japan, 83, 551-576.

Endo, H., A. Kitoh, R. Mizuta, and M. Ishii, 2017: Future changes in precipitation extremes in East Asia and their uncertainty based on large ensemble simulations with a high-resolution AGCM. SOLA, 13, 7-12.

Fujibe, F., 2001: On the near- $0^{\circ} \mathrm{C}$ frequency maximum in surface air temperature under precipitation: A statistical evidence for the melting effect. J. Meteor. Soc. Japan, 79, 731-739.

Fujita, M., H. G. Takahashi, N. N. Ishizaki, and F. Kimura, 2014: Long-term variation of winter precipitation linked to sea-surface heat fluxes around the Japan/East Sea. Atmos. Sci. Lett., 15, 275-281.

Fujiyoshi, Y., T. Fujita, T. Takeda, T. Kojiri, K. Takara, and S. Ikeda, 1996: The effect of complex terrain on the leeside distribution of snowfall-In the case of Nobi Plain-. Tenki, 43, 391-408 (in Japanese).

Hirai, M., and M. Oh'izumi, 2004: Development of a new land-surface model for JMA-GSM. Proceeding of 20th Conf. Wea. Anal. Forecasting/16th Conf. NWP, 2.22 p. [Available at https://ams.confex.com/ams/ 84Annual/techprogram/paper_68652.htm.]

Hirose, N., and K. Fukudome, 2006: Monitoring the Tsushima warm current improves seasonal prediction of the regional snowfall. SOLA, 2, 61-63.

Honda, M., A. Yamazaki, A. Kuwano-Yoshida, Y. Kimura, and K. Iwamoto, 2016: Synoptic conditions causing an extreme snowfall event in the Kanto-Koshin district of Japan on 14-15 February 2014. SOLA, 12, 259-264.

Ikawa, M., H. Mizuno, T. Matsuo, M. Murakami, Y. Yamada, and K. Saito, 1991: Numerical modeling of the convective snow cloud over the Sea of Japan-Precipitation mechanism and sensitivity to ice crystal nucleation rates. J. Meteor. Soc. Japan, 69, 641-667.

Ishizaki, N. N., I. Takayabu, M. Oh'izumi, H. Sasaki, K. Dairaku, S. Iizuka, F. Kimura, H. Kusaka, S. A. Adachi, K. Kurihara, K. Murazaki, and K. Tanaka, 2012: Improved performance of simulated Japanese climate with a multi-model ensemble. J. Meteor. Soc. Japan, 90, 235-254.

Iwamoto, K., S. Nakai, and A. Sato, 2008: Statistical analyses of snowfall distribution in the Niigata area and its relationship to the wind distribution. SOLA , 4, 45-48.

Iyobe, T., T. Matsumoto, K. Kawashima, and K. Izumi, 2015: Detailed spatial distribution characteristics of snow depth due to the exceptional February 2014 snowfall event associated with the passage of a cyclone along the southern coast of Honshu Island. Seppyo, 77, 411-419 (in Japanese with English ab- 
stract).

Kain, J. S., and J. M. Fritsch, 1993: Convective parameterization for mesoscale models: The Kain-Fritsch scheme, in the representation of cumulus convection in numerical models. Meteor. Monogr., 24, Emanuel, K. A., and D. J. Raymond (eds.), Amer. Meteor. Soc., Boston, 165-170.

Kawase, H., H. Sasaki, A. Murata, M. Nosaka, and N. N. Ishizaki, 2015: Future changes in winter precipitation around Japan projected by ensemble experiments using NHRCM. J. Meteor. Soc. Japan, 93, 571-580.

Kawase, H., A. Murata, R. Mizuta, H. Sasaki, M. Nosaka, M. Ishii, and I. Takayabu, 2016: Enhancement of heavy daily snowfall in central Japan due to global warming as projected by large ensemble of regional climate simulations. Climatic Change, 139, 265-278.

Kawashima, K., T. Matsumoto, T. Iyobe, and K. Izumi, 2015: Spatio-temporal changes in precipitation type and its relationships with snow damages during the heavy snowfall event in the Kanto-Koshin district, February 2014. Seppyo, 77, 313-325 (in Japanese with English abstract).

Kitagawa, H., 2000: Radiation processes. Separate vol. ann. rep. $N P D, 46,16-31$ (in Japanese).

Kobayashi, S., Y. Ota, and Y. Harada, A. Ebita, M. Moriya, H. Onoda, K. Onogi, H. Kamahori, C. Kobayashi, H. Endo, K. Miyaoka, and K. Takahashi, 2015: The JRA-55 Reanalysis: General specifications and basic characteristics. J. Meteor. Soc. Japan, 93, 5-48.

Mizuta, R., A. Murata, M. Ishii, H. Shiogama, K. Hibino, N. Mori, O. Arakawa, Y. Imada, K. Yoshida, T. Aoyagi, H. Kawase, M. Mori, Y. Okada, T. Shimura, T. Nagatomo, M. Ikeda, H. Endo, M. Nosaka, M. Arai, C. Takahashi, K. Tanaka, T. Takemi, Y. Tachikawa, K. Temur, Y. Kamae, M. Watanabe, H. Sasaki, A. Kitoh, I. Takayabu, E. Nakakita, and M. Kimoto, 2017: Over 5000 years of ensemble future climate simulations by $60 \mathrm{~km}$ global and $20 \mathrm{~km}$ regional atmospheric models. Bull. Amer. Meteor. Soc., 98, 1383-1398.

Murata, A., H. Sasaki, H. Kawase, M. Nosaka, M. Oh'izumi, T. Kato, T. Aoyagi, F. Shido, K. Hibino, S. Kanada, A. Suzuki-Parker, and T. Nagatomo, 2015: Projection of future climate change over Japan in ensemble simulations with a high-resolution regional climate model. SOLA, 11, 90-94.

Nagata, M., M. Ikawa, S. Yoshizumi, and T. Yoshida, 1986: On the formation of a convergent cloud band over the Japan Sea in winter; numerical experiments. $J$. Meteor. Soc. Japan, 64, 841-855.

Nakanishi, M., and H. Niino, 2004: An improved MellorYamada level-3 model with condensation physics: Its design and verification. Bound.-Layer Meteor., 112, 1-31.

Ohigashi, T., and K. Tsuboki, 2007: Shift and intensification processes of the Japan-Sea Polar-Airmass Convergence Zone associated with the passage of a midtropospheric cold core. J. Meteor. Soc. Japan, 85, 633-662.

Saito, K., M. Murakami, T. Matsuo, and H. Mizuno, 1996: Sensitivity experiments on the orographic snowfall over the mountainous region of northern Japan. $J$. Meteor. Soc. Japan, 74, 797-813.

Sasaki, H., K. Kurihara, I. Takayabu, and T. Uchiyama, 2008: Preliminary experiments of reproducing the present climate using the non-hydrostatic regional climate model. SOLA, 4, 25-28.

Suda, K., and K. Ueno, 2014: Weather divide in winter season in Japan analyzed by AMeDAS data. J. Geogr. (Chigaku Zasshi), 123, 35-47 (in Japanese with English abstract).

Takahashi, H. G., N. N. Ishizaki, H. Kawase, M. Hara, T. Yoshikane, X. Ma, and F. Kimura, 2013: Potential impact of sea surface temperature on winter precipitation over the Japan Sea side of Japan: A regional climate modeling study. J. Meteor. Soc. Japan, 91, 471-488.

Takano, I., 2002: Analysis of an intense winter extratropical cyclone that advanced along the south coast of Japan. J. Meteor. Soc. Japan, 80, 669-695.

Wakisaka, Y., 1986: Regional characteristics in the distribution of precipitation during the winter monsoon in Japan. Geogr. Rev. J., 59, 85-97 (in Japanese with English abstract).

Yabu, S., S. Murai, and H. Kitagawa, 2005: Clear sky radiation scheme. Separate vol. ann. rep. NPD, 51, 53-64 (in Japanese).

Yamamoto, A., 1984: Snowfalls in Kanto Plain-Threshold air temperature for snow falls in the melting layer-. $J$. Meteor. Res., 36, 131-149 (in Japanese).

Yamazaki, A., M. Honda, and A. Kuwano-Yoshida, 2015: Heavy snowfall in Kanto and on the Pacific Ocean side of northern Japan associated with western Pacific blocking. SOLA, 11, 59-64. 